\title{
Una nueva excavación en la iglesia de Sant Quirze de Pedret (Cercs, Barcelona)
}

\author{
Alberto López Mullor * \\ Alvar Caixal Mata *
}

\section{INTRODUCCIÓN}

La iglesia de Sant Quirze de Pedret es uno de los monumentos más genuinos de la arquitectura anterior al románico en Cataluña. Su valoración se produjo a finales de siglo pasado y principios del nuestro (Muns 1887; Puig I Cadafalch, Falguera, Goday 1909; Gómez Moreno 1919; Puig I CADAFAlCH, 1928), debido a sus especiales caracteres estilisticos: conservaba algunos arcos de herradura y buena parte de la planta original, creciendo su fama, años más tarde, a causa de la aparición de una serie de murales, fechables en dos etapas, de los siglos $x$ y $x \|$ respectivamente (Puiggari 1889; Gudiol 1937; estado de la cuestión en Rosell 1985; Yarza 1985).

Los origenes del templo se han querido llevar a la época visigótica (Pallás 1962), y en todo caso, su fábrica se ha integrado dentro de 10 "mozárabe" (Gómez Moreno 1919; Puig I Cadafalch, Falguera, Goday 1909). Por la bibliografía que llevamos citada podría suponerse que el edificio se encuentra perfectamente estudiado, habiéndose resuelto todos los problemas interpretativos que pudiera plantear. Sin embargo, no es asi. Son notables los análisis de la decoración pictórica, algunos de ellos muy recientes, pero todavía existe disparidad de criterios sobre la interpretación de la arquitectura, habiéndose barajado hipótesis muy distintas. El desacuerdo es tal que se refiere incluso a la tipologia del templo original:

\footnotetext{
- Servicio de Patrimonio Arquitectónico. Diputación de Barcelona.
} 
hay quien considera que fue de nave única (PALLAS 1962; SITJES 1977; JUNYENT 1983), mientras otros sostienen que tuvo tres espacios (Muns 1887; Puig I Cadafalch, Falguera, Goday 1909; Gómez Moreno 1919; Gudiol 1937; BARRAL 1981; PONS 1985).

El Servicio de Catalogación y Conservación de Monumentos de la Diputación de Barcelona (hoy de Patrimonio Arquitectónico) realizó una primera restauración del edificio en la década de los sesenta (1959-1964). Las obras fueron acompañadas de un estudio de la fábrica, sobre el que luego volveremos. Sin embargo, la metodologia utilizada, propia de la época, aun permitiendo un grado de conocimiento del templo bastante considerable, dejó ciertos cabos sueltos en la interpretación final y la vieja polémica no quedó zanjada definitivamente (algunos resultados de la investigación en PALLAS 1962).

En 1989, el mismo Servicio, a petición del ayuntamiento de Berga - - a quien el obispado de Solsona, propietario del inmueble, ha confiado el mantenimiento del templo-, emprendió nuevas obras. Se trataba de hacer una "restauración de la restauración", ante el mal estado general de la iglesia. En esta nueva intervención, asumida por un equipo pluridisciplinar *, se pretendia lógicamente arreglar los desperfectos que presentaba la iglesia, pero también hacer inteligible el monumento, recreando formal y ambientalmente su apariencia genuina. Una operación de esta indole, llevada a término con la metodología que venimos desarrollando hace casi una década (cf.: GonzÁlez 1985; Idem 1990; LOPEZ MulloR 1986; Idem 1990), habria de incluir la recopilación de las fuentes documentales, la investigación de historia del arte, la excavación arqueológica, el análisis arquitectónico, el estudio de materiales y técnicas constructivas, etc. Naturalmente confiabamos que este proceso desvelaria de una vez por todas la evolución arquitectónica del templo y la cronología de sus diversas fases, poniendo fin a una discusión ya casi secular.

Parece que, por ahora, estamos en camino de conseguir nuestro objetivo, pese a las dificultades que se han ido planteando y, aunque la investigación no ha concluido, hemos querido presentar aquí los resultados de la primera campaña de excavación (1989), y las últimas novedades proporcionadas por la segunda, llevada a cabo en 1991.

\section{DESCRIPCIÓN DEL EDIFICIO (LÁMS. I.1, XII)}

Para comprender el resto de la exposición resulta ineludible pergeñar brevemente el estado en que se encontraba la iglesia antes de la primera 
Una nueva excavación en la iglesia de Sant Quirze de Pedret ...
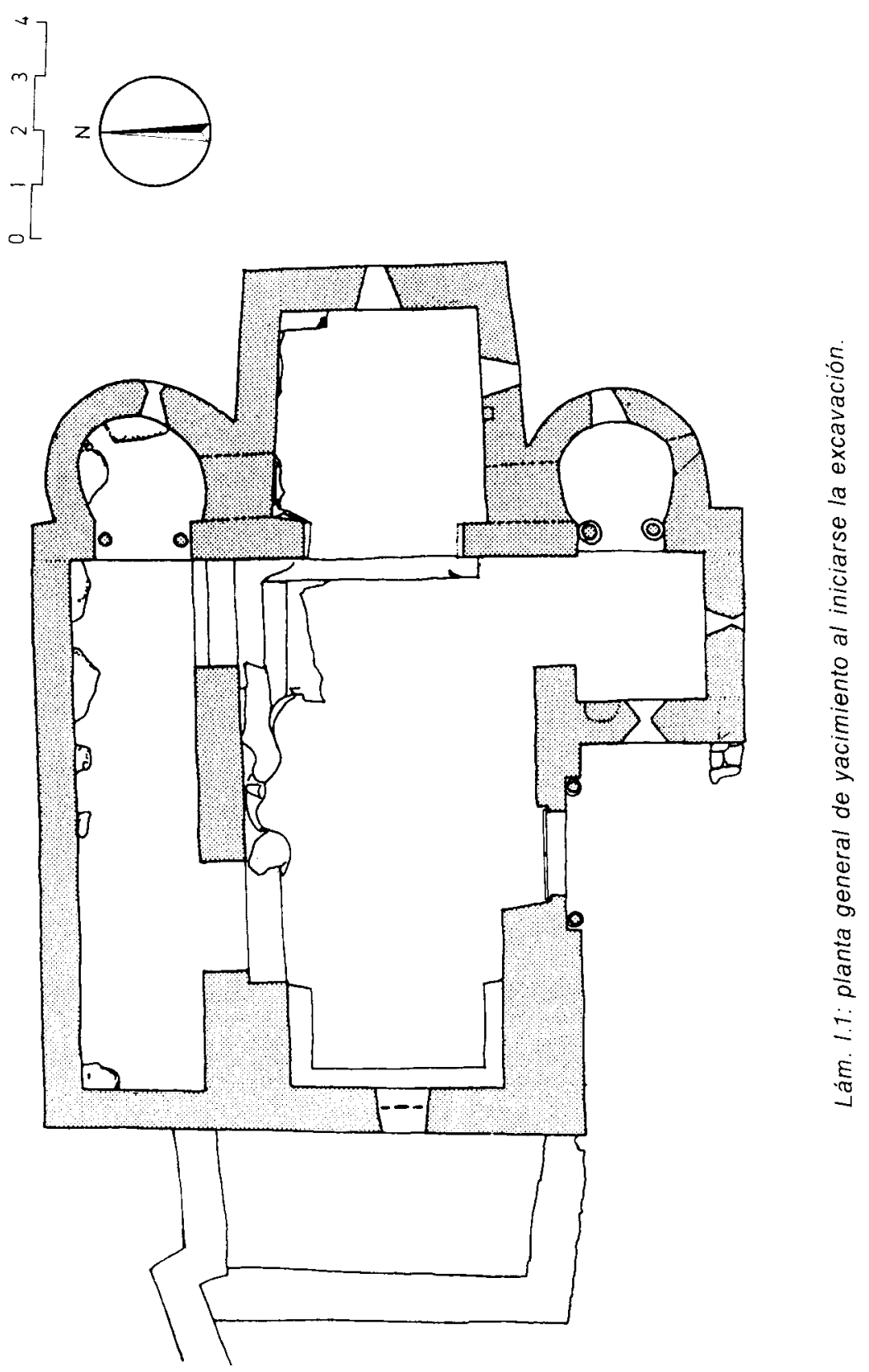


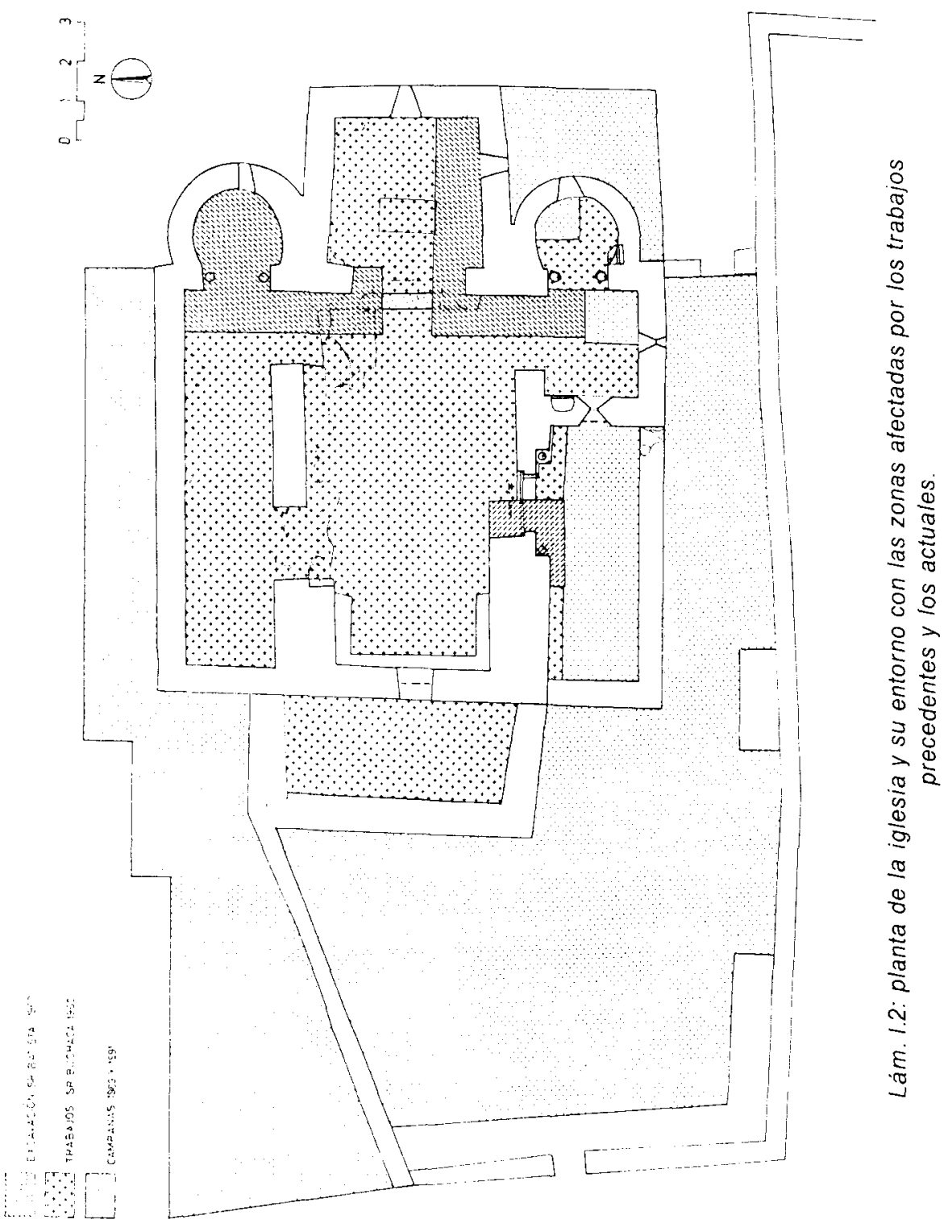


restauración de los años sesenta. De este modo el lector podrá hacerse mejor una idea del alcance de las hipótesis de trabajo que luego presentaremos.

El templo está enclavado en la vertiente meridional de una colina que presenta una acusada pendiente natural hacia mediodia. Desde ella se domina el curso del río Llobregat, a poniente, y un extenso paraje de la comarca de Berguedà, caracterizado por la sucesión de elevaciones cubiertas de bosques que dan lugar a estrechos valles.

En 1959, el edificio se componia esencialmente de dos naves: la mayor y la septentrional; en el ángulo sudeste presentaba otro espacio que ocupaba sólo un tercio de la superficie de los restantes. Estos tres cuerpos estaban encabezados, al este, por sendos ábsides laterales de planta en forma de herradura y un elemento central de trazado trapezoidal. La absidiola sur presenta dos aspilleras de derrame único, una en el eje y otra a mediodia; la del norte tenía una abertura axial de doble derrame culminada en arco de medio punto. La cabecera principal presentaba en el centro una ventana de derrame simple (en 1960 se localizó otra del mismo tipo en la cara sur).

En la fachada meridional de la nave mayor, se conservaba una puerta de estilo románico avanzado, con arquivoltas lisas apoyadas en lineas de imposta, flanqueadas por capiteles decorados sostenidos por una columna estrigilada, al oeste, y otra de tipo salomónico al este, ambas provistas de basa. En la parte alta de este lienzo podian observarse tres finas aspilleras de derrame único, tapiadas interiormente (también fueron liberadas en 1960). La fachada septentrional era lisa. No asi la occidental, en la que se distinguian tres ventanas superpuestas, aunque no alineadas según un eje vertical colocadas en el testero de la nave mayor. La más alta, casi en el límite con la cubierta, se encontraba tapiada y parecía acabar en arco de medio punto; la del centro, tambièn estaba tapiada y la más baja, de grandes proporciones, presentaba arco de medio punto algo sobrepasado. Este último vano tenia trazas de haber sido retocado.

Debe destacarse que la altura de la nave central era bastante superior a la de los elementos colaterales (en 1960 se rebajaron todas las cubiertas). En la cima del testero occidental se asentaba una gran espadaña de dos ojos, a la que se accedia desde el norte a través de unas escaleras apoyadas en la cúspide de la fachada occidental. En la parte superior del testero oriental existía una ventana geminada con doble arco de herradura (descubierta en 1960). Sobre la cabecera central se elevaba un elemento añadido donde, al parecer, habia un horno doméstico (según amable información del prof. M. Riu), y cuya presencia ocultaba la visión de la ventana descrita. Por fin, el cuerpo de mediodía tenia, al sur y al este, 
sendas ventanas de doble derrame acabadas en arco de medio punto. Todo el conjunto estaba cubierto por un tejado a dos aguas, a excepción de los elementos de la cabecera que poseian cubiertas semicónicas en los lados y a dos vertientes en el centro.

Exteriormente, se percibia un aparejo de ripios desiguales que, en general, no formaban hiladas, cubiertos por múltiples y heterogéneas capas de enlucido. Con todo, las esquinas de la fábrica estaban marcadas con bloques de mejor factura, cuya talla era muy próxima a los sillares, y a los que, para simplificar, denominaremos asi en los sucesivo. El aspecto interior del edificio no dejaba de asombrar. Sólo se utilizaba para el culto la nave mayor; sus gruesas paredes se hallaban enlucidas y pintadas con una decoración que destacaba los ángulos de la fábrica imitando piedras bien encuadradas. El pavimento era de losetas cerámicas cuadradas aunque al norte afloraban algunos vestigios de la roca natural no desbastada. La cubierta era una bóveda de cañón apuntado apoyada en grandes arcos formeros de medio punto, los cuales, en el lado septentrional, se habian aprovechado para instalar sendas capillas. En el lado meridional, el arco del sudeste servia de acceso a un pequeño santuario, cuya superficie ocupaba el cuerpo de mediodía descrito al principio; este elemento poseía una bóveda de arista construida con ladrillo y el suelo era de losetas (tanto este pavimiento como el de la nave mayor fueron sustituidos por losas de piedra en la restauración de 1959-1964). El arco formero del suroeste enmarcaba interiormente la puerta del templo.

El presbiterio, convenientemente realzado, se encontraba en la cabecera central. Su embocadura poseia un arco triunfal de medio punto $y$, una vez en el interior, se podian observar dos puertas rectangulares, colocadas a ambos lados del lugar destinado al oficiante, las cuales constituían el único paso a las absidiolas. De éstas, la meridional se utilizaba como sacristía, y en ella era visible el acceso original, entonces tapiado, pero todavia coronado por un arco de herradura, razonablemente conservado hasta las impostas, pero falto de los apoyos laterales en forma de columnas, que algún dia parecía haber tenido a juzgar por la presencia de sus basas. La absidiola norte habia perdido el arco de herradura primitivo, y presentaba una embocadura desproporcionadamente grande, acabada toscamente en forma de medio punto. Desde esta absidiola se podia pasar al tercio oriental de la antigua nave norte, separado del resto por un tabique que presentaba una puertecita. Después de franquearla, se llegaba al otro sector de la nave, el lugar más recóndito del edificio, donde se podia advertir la presencia de dos aberturas tapiadas exteriormente. De nuevo se trataba de elementos acabados en arco de herradura, dotados de dovelas muy estilizadas e impostas bien marcadas. La situación de estos elementos coincidia, aunque no exactamente, con el lugar 
que ocupaban las dos capillas que hemos descrito al tratar del muro norte de la nave mayor. Todo este espacio lateral se hallaba cubierto por una bóveda aproximadamente de cuarto de cañón algo achatada.

Para terminar, deben citarse las ruinas de un cuerpo rectangular que se entregaba a la fachada de poniente, el cual tenía al descubierto la pared septentrional y parte de la occidental (el perimetro exacto se delimitó en 1960). Debe destacarse que su aparejo diferia con mucho del empleado en la iglesia, ya que estaba compuesto por sillarejo bien tallado y colocado a soga y tizón. Igualmente, se ha de añadir que, en una cota inferior a la terraza artificial donde está el templo e inmediatamente a mediodía, se alzaba una masía cuyos muros de tapial presentaban zócalos de piedra, siendo del mismo material algunas ruinas que se observaban en los alrededores. Todos estos vestigios poseian un aparejo idéntico al del añadido arruinado que se ha descrito.

\section{LA EXCAVACIÓN ARQUEOLÓGICA}

\section{I1.1. Antecedentes}

En febrero de 1960, el Museo Arqueológico de Barcelona, a petición del Servicio de Catalogación y Conservación de Monumentos que debia restaurar el edificio, desarrolló una primera y corta campaña, dirigida por el señor Ricardo Batista. Sus resultados fueron reflejados en una memoria que se entregó al profesor Luis Pericot, a la sazón comisario provincial de excavaciones, la cual ha permanecido inédita hasta hoy (salvo algunas referencias concretas en Pallás, 1962). No obstante, el señor Batista, actual director del museo citado, conservaba un "diario de excavación" manuscrito que nos ha cedido amablemente (BATISTA 1960), gracias al cual hemos podido desentrañar las claves principales de su actuación.

De este modo, sabemos que en aquella fecha se realizó un sondeo en el ángulo sudeste de la nave mayor, otro que interesó parte del extremo oriental de la parcialmente desaparecida nave sur (cata realizada dentro del cuerpo sudeste actual), y un tercero que comprendió sectores contiguos de la cabecera principal y de la absidiola de mediodía. Además, se excavaron los niveles más superficiales de la zona exterior colindante con la puerta (lám. l.2).

La información proporcionada por estas catas, además de resultar por si misma de un valor inestimable, ayuda a comprender algunos aspectos de otros trabajos que se llevaron a cabo a continuación. Nos referimos a 
una serie de sondeos practicados tanto en el interior como en el exterior del edificio, bajo la supervisión del señor Modesto Buchaca, constructor de la localidad de Berga que llevó a cabo las primeras obras de restauración. En este ocasión, de acuerdo con las indicaciones del arquitecto Camilo Pallás, director de las citadas obras, se simultanearon los trabajos de construcción con la exploración de la iglesia, y durante los meses de marzo a junio de 1960 se llevaron a cabo una serie de trincheras en el cuerpo sudeste, la absidiola de mediodia, la cabecera central y la nave mayor; ya en el exterior, también se abrieron sondeos en las ruinas del cuerpo añadido de poniente y en la zona colindante al ángulo suroeste de la fábrica (lám. I.2).

De todos estos trabajos, como de las obras propiamente dichas, el referido señor Buchaca también redactó un detallado "diario" dando pormenores sobre los descubrimientos realizados, los cuales se acompañaron de una serie de plantas y secciones parciales (Buchaca 1960). Todo este material ha permanecido inédito hasta hoy, aun cuando ha podido ser consultado por algunos investigadores, y a principios de 1991 su autor nos cedió gentilmente una copia del mismo, para ser utilizada en nuestras investigaciones.

Después de estas dos actuaciones, la parte del yacimiento donde era posible desarrollar nuevos trabajos quedó sensiblemente mermada. En el interior del templo, sólo subsistieron sendos testigos en la absidiola meridional y el cuerpo sudeste. En el exterior, quedó vacia el área de las ruinas del elemento añadido de poniente y también se vieron afectados algunos estratos superficiales de la zona contigua a la fachada sur.

Por otra parte, los materiales que se recogieron en 1960 durante la actuación del señor Buchaca, se han perdido en su mayor parte, a excepción de algunas piezas singulares que se depositaron en el Museo Municipal dè Berga (recientemente se han dado a conocer algunas de ellas: VIGUÉ 1985: 234, 236; Bolós, RIU, C. 1985 b: 235-236). Con todo, y a pesar de la pérdida irreparable de las cerámicas descubiertas en los estratos más profundos, se dispone de algunos testimonios sumamente útiles, como las fotografias de las monedas y el croquis de su situación en el yacimiento en el momento de ser halladas. Este numerario, estudiado a través de las fotos por la señora Maria Clua, conservadora del Gabinete Numismático de Cataluña, ha servido de gran ayuda para la datación de las fases más tardias del yacimiento y para confirmar la cronologia de algunos hallazgos recientes. 


\section{III.2. Objetivos y método}

Con tales antecedentes, el planteamiento de la excavación resultaba problemático. En un principio ignorábamos la existencia de los dos pequeños testigos interiores en el área meridional, y tampoco estábamos muy seguros del alcance de los trabajos en el entorno del templo. Con todo, la sola comprobación de las relaciones físicas de los distintos elementos de la iglesia y su estudio con método y mentalidad arqueológicas, ya justificaba una excavación. Máxime teniendo en cuenta los problemas que la interpretación y datación del edificio habian venido planteando.

La principal meta de la investigación era la habitual en las actuaciones de nuestro Servicio: averiguar la configuración física de cada una de las fases del edificio, determinar su datación relativa y absoluta y, con ayuda del estudio de las fuentes y la historia del arte, aproximarnos a la funcionalidad y significado de sus elementos. A pesar de que en este caso tal cúmulo de objetivos resultaba dificil de alcanzar, dadas las carencias apuntadas, habia que dispensar al yacimiento la misma o mayor atención que merecen los que se encuentran intactos.

En consecuencia, durante la primera campaña de excavación se estudió en primer término el lugar que mayor dificultad planteaba: el interior del templo actual. A continuación, se analizó otro sector alterado, el cuerpo añadido de poniente y, por fin, se pasó al terreno contiguo a las paredes perimetrales norte y sur, donde existian posibilidades de hallar una estratigrafia fiable. Alentados por los excelentes e inesperados resultados de la primera campaña, en la segunda se ha insistido en la franja comprendida entre la fachada sur del edificio y el muro de contención de la terraza actual; también se ha realizado un provechoso sondeo al noroeste de la fábrica, que ha afectado por igual al cierre occidental de la nave norte y al muro septentrional del añadido en ruinas que se conserva al oeste de la iglesia. En este momento la intervención continúa, ampliándose este sondeo hacia el oeste.

\section{III.3. Desarrollo de los trabajos (láms. II, VIII-IX, XII-XIV)}

La excavación del interior de la iglesia empezó en las naves mayor y meridional y sus cabeceras respectivas. El espacio septentrional y su absidiola se postergaron momentáneamente, pues su separación física en relación con el resto del área interna del edificio (se encuentran en una cota más alta) asi lo aconsejaba. Además, estos ámbitos carecian del pavimento de losas colocado tras la primera restauración, el cual sellaba el conjunto restante. 


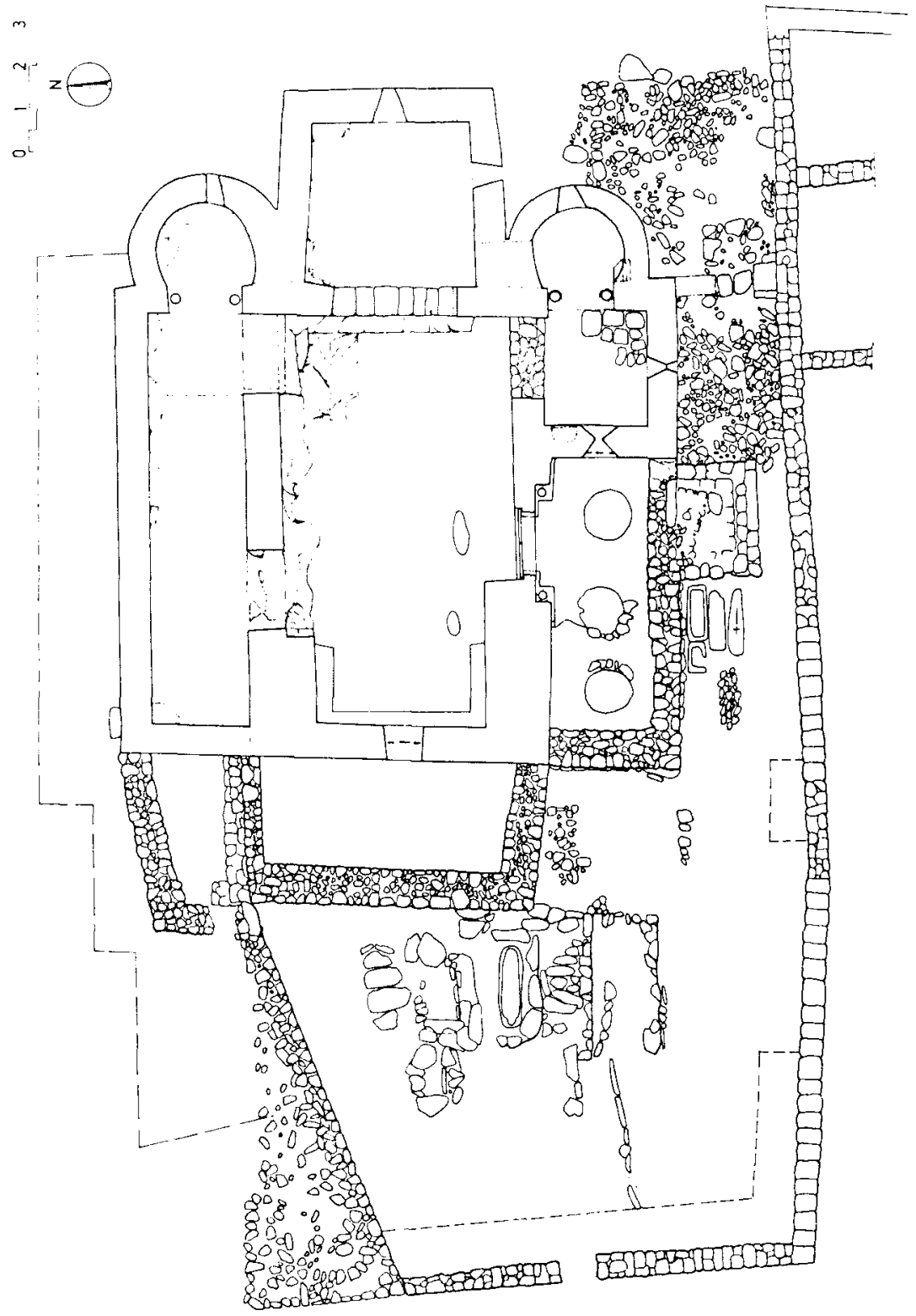

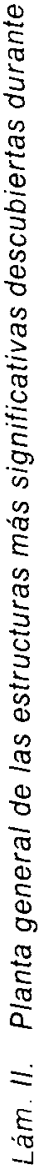


Esta primera acción conllevó algunos descubrimientos (“redescubrimientos" en ciertos casos) del mayor interés. En primer lugar, no bien se hubo retirado el pavimento moderno, apareció arrasado el muro de separación entre las naves mayor y meridional (lám. XII.2). Esta pared ya fue documentada por el señor Batista pero, al permanecer inédita su excavación, no habia sido mencionada explicitamente en la bibliografía posterior. En segundo lugar, se comprobó la benéfica presencia de los testigos estratigráficos mencionados $y$, en tercer lugar, se advirtió que las jambas y columnas del arco triunfal de la absidiola meridional se apoyaban sobre un muro de arriostramiento que, al norte, se entregaba limpiamente a la pared de mediodia de la nave mayor. Además, dentro del ámbito de la absidiola mencionada, también se documentó la presencia de una tumba recortada en el terreno natural (ya excavada; BuCHACA 1960: 24 , sección G-I-E). Hallazgos de igual indole se realizaron en la nave central, donde desgraciadamente habia desaparecido cualquier vestigio estratigráfico, pero se conservaban intactas las cimentaciones de los muros perimetrales, asi como fragmentos de construcciones posteriores.

La excavación de la nave norte y su cabecera no produjo sorpresas, pues la potencia estratigráfica en estos lugares era escasa de antiguo, debido a la gran altura de la roca natural, y donde existió alguna habia desaparecido por completo durante los trabajos de quienes nos precedieron. En el sector oeste extramuros de la iglesia se documentó toda la planta del añadido, parte de cuyas paredes se encontraban a la vista (descubiertas y vueltas a tapar parcialmente, BuCHACA 1960: 35 ss.), y se empezó a localizar la extensa e interesante necrópolis de la sagrera altomedieval. En el terreno contiguo a la fachada septentrional del edificio, que habia permanecido intacto, fue posible establecer una sucesión de los distintos suelos utilizados, y fecharlos.

A mediodía de la iglesia se empezó excavando el área que imaginábamos debió albergar la nave sur del edificio del siglo $x$. A juzgar por las fotos de los trabajos del arquitecto Camilo Pallás y por las plantas hipotéticas que publicó, esperábamos encontrar esta zona prácticamente vacia, pero felizmente no fue así. El lugar más afectado era el entorno de la puerta actual, donde se habia extraido buena parte de los estratos más tardios y numerosos enterramientos (BATISTA 1960: 19-21); también se había practicado una trinchera paralela a la fachada (BuchacA 1960: 35 ss.). Sin embargo, las tumbas descubiertas por Batista, básicamente de los siglos XVI al XIX, y que nosotros hemos seguido localizando con gran profusión, debieron desanimar a los continuadores de su labor, que dejaron intacta buena parte del sedimento arqueológico. Gracias a este hecho, hemos podido documentar el cementerio descrito, con enterramientos modernos pero también medievales. Además, se han localizado tres silos, 
abandonados en el siglo xII y, lo que es más importante, la planta completa del tramo desaparecido de la nave sur, los vestigios de su arrasamiento en época medieval, y el trazado de un recinto algo precario, seguramente un porche, que ocupó su misma área a finales del medioevo (láms. II, XIV).

Durante la segunda campaña se ha continuado insistiendo en este sector, ya extramuros de la antigua nave sur, donde han aparecido las escaleras que conducian a la puerta principal del edificio del siglo x llám. II). También aqui se ha encontrado un interesante relleno, datable en el siglo XIII, que comprende los restos de las paredes del tramo del cuerpo meridional arruinado, y que además contenia interesantes piezas singulares, como las impostas, los capiteles y los fustes de una entrada acabada en arco de herradura; también se han encontrado capiteles mensuliformes con decoración vegetal esquemática.

Por último, cabe reseñar los hallazgos realizados en un nuevo sondeo abierto fuera de la iglesia, al noroeste de la fábrica que, afectando por igual a la fachada occidental de la nave norte y al cuerpo añadido de poniente, ha permitido fechar la fundación de este último elemento en el siglo $x \mathrm{I}, \mathrm{y}$ advertir la presencia de algunas estructuras anteriores.

\section{RESULTADOS}

En el estado actual de nuestros trabajos, sus conclusiones sólo pue den ser provisionales, y con tal carácter las presentamos. Sin embargo, ya nos han permitido confirmar algunos datos y formular ciertas hipótesis que nos parecen sugestivas.

\subsection{Primera fase, ca. finales siglo Ix principios del siglo x (lám. III,} a $y$ b)

A nuestro entender, el primer edificio existente en el área excavada era una pequeña iglesia de nave única y cabecera trapezoidal, cuya planta coincidia con la de la nave y el ábside mayor conservados hasta hoy. Los muros perimetrales de esta construcción permanecen en la fábrica que ha llegado a nosotros, aunque alterados por intervenciones posteriores. En cuanto a la comunicación entre el presbiterio y el espacio destinado a los fieles, parece que en la excavación del Museo Arqueológico de Barcelona se evidenció que, antes del actual, hubo otro arco triunfal de menor luz (BATISTA 1960: 8-12), el cual se supuso de herradura (PALL.As 
1962), algunas de cuyas dovelas podrian haberse conservado en el que ha subsistido.

El aparejo de esta primera construcción era muy sencillo, lo conocemos a través de los vestigios que permanecen a la vista y los descubiertos en la excavación. Tanto exterior como interiormente, se trataba de mamposteria a base de ripios unidos con mortero de cal, los cuales no formaban hiladas. Los ángulos de la fábrica poseian sillares alargados bien escuadrados y mejor colocados.

Suponemos que la puerta de esta iglesia debió encontrarse a occidente, teniendo en cuenta tres clases de evidencias. Por una parte, la presencia en este punto de una ventana de proporciones relativamente grandes, cuyas jambas podrian haber sido algo modificadas en el siglo xill (infra: 4.4). Por otra parte, el argumento ex silentio proporcionado por la excavación, al no haberse encontrado ningún vestigio de la puerta en el paramento sur: téngase en cuenta que en un principio la cota externa de este lienzo era bastante más baja que la actual, y los trabajos arqueológicos han permitido explorar toda su cimentación y una buena parte de la pared vista. Finalmente, creemos muy ilustrativo el hallazgo, a poniente del testero, de una serie de plataformas escalonadas, formadas a finales del siglo $\mathrm{I}$, según se desprende de los materiales cerámicos asociados (lám. IX), las cuales culminaban justamente al pie del lugar donde situamos el acceso a la iglesia.

La identificación de esta abertura como puerta no constituye una novedad, pues ya tratan de ella Gómez Moreno (1919: 62), Gudiol (1937: 112), Sitjes (1977: 116) y Barral (1981: 180). Todos ellos, sin embargo, la identifican como pasaje al cuerpo de poniente, lo cual no deja de ser cierto en época posterior, sin caer en la cuenta, por diversas razones, que debia ser el acceso primitivo al templo. Si además damos por buena la hipótesis de Junyent sobre la identidad formal entre el arco triunfal y el de la puerta de las iglesias prerrománicas catalanas, la morfologia de la ventana podria sugerir que el primer arco del presbiterio de Pedret, desaparecido pero de cuyas jambas se conoce la situación (BATISTA 1960; SiTJES 1977: 115, le da una luz de 1,70 m, este dato no lo publicó Pallás; quizá el autor lo sacó del diario de Buchaca, donde se hace un resumen de los trabajos de Batista), pudo haber sido similar a los de Cuixà o, en general, a los de la Cataluña francesa, atendiendo a la morfologia de la ventana que nos ocupa. Todo ello, de momento, no deja de ser una especulación, pero bueno será tenerlo en cuenta, a la espera de allegar nuevos datos.

En el eje del ábside se conserva una abertura original con derrame único, acabada en un arco toscamente trazado de perimetro próximo al medio punto. La ventana sur, al decir de algunos autores (p. ej.: YARZA 


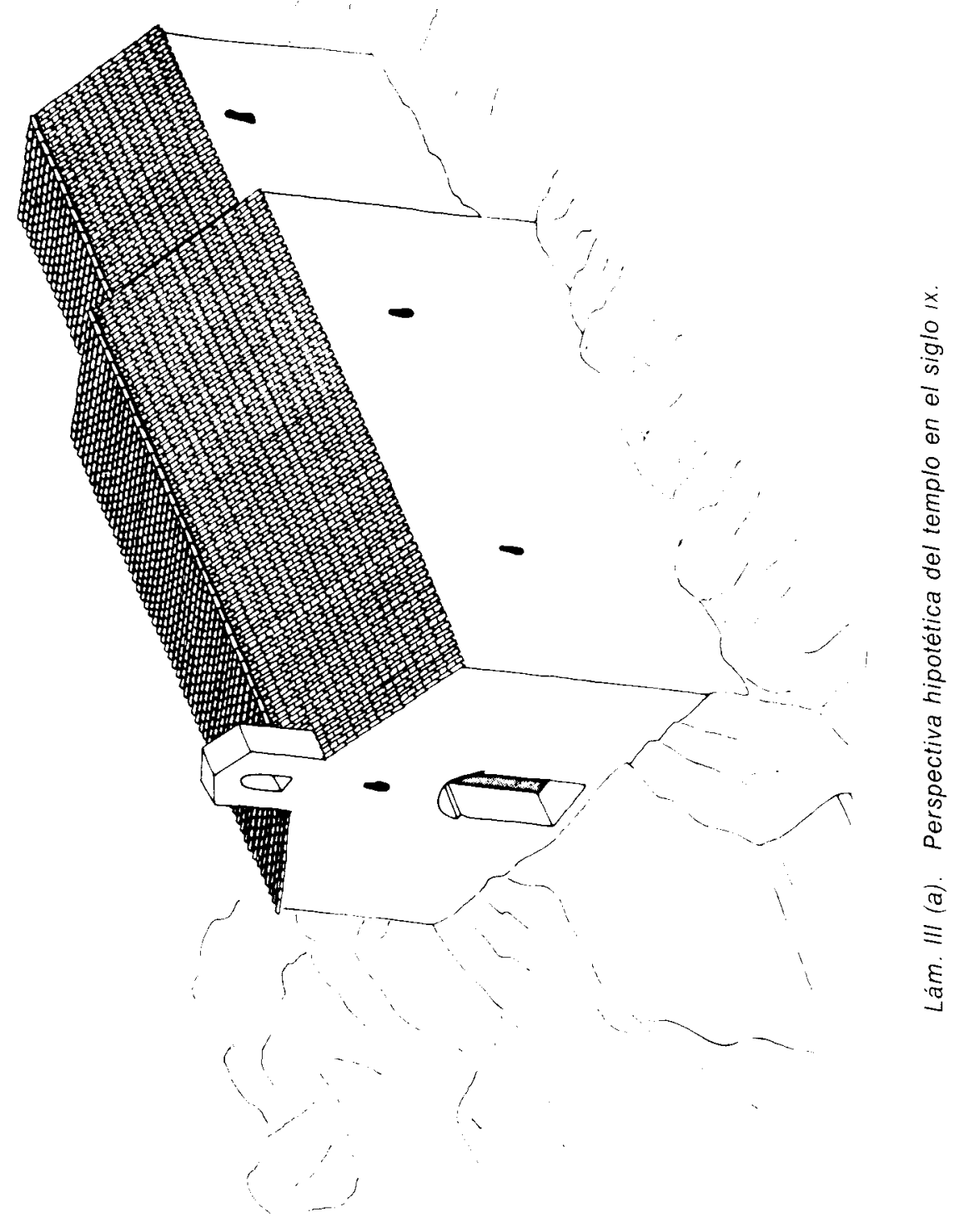



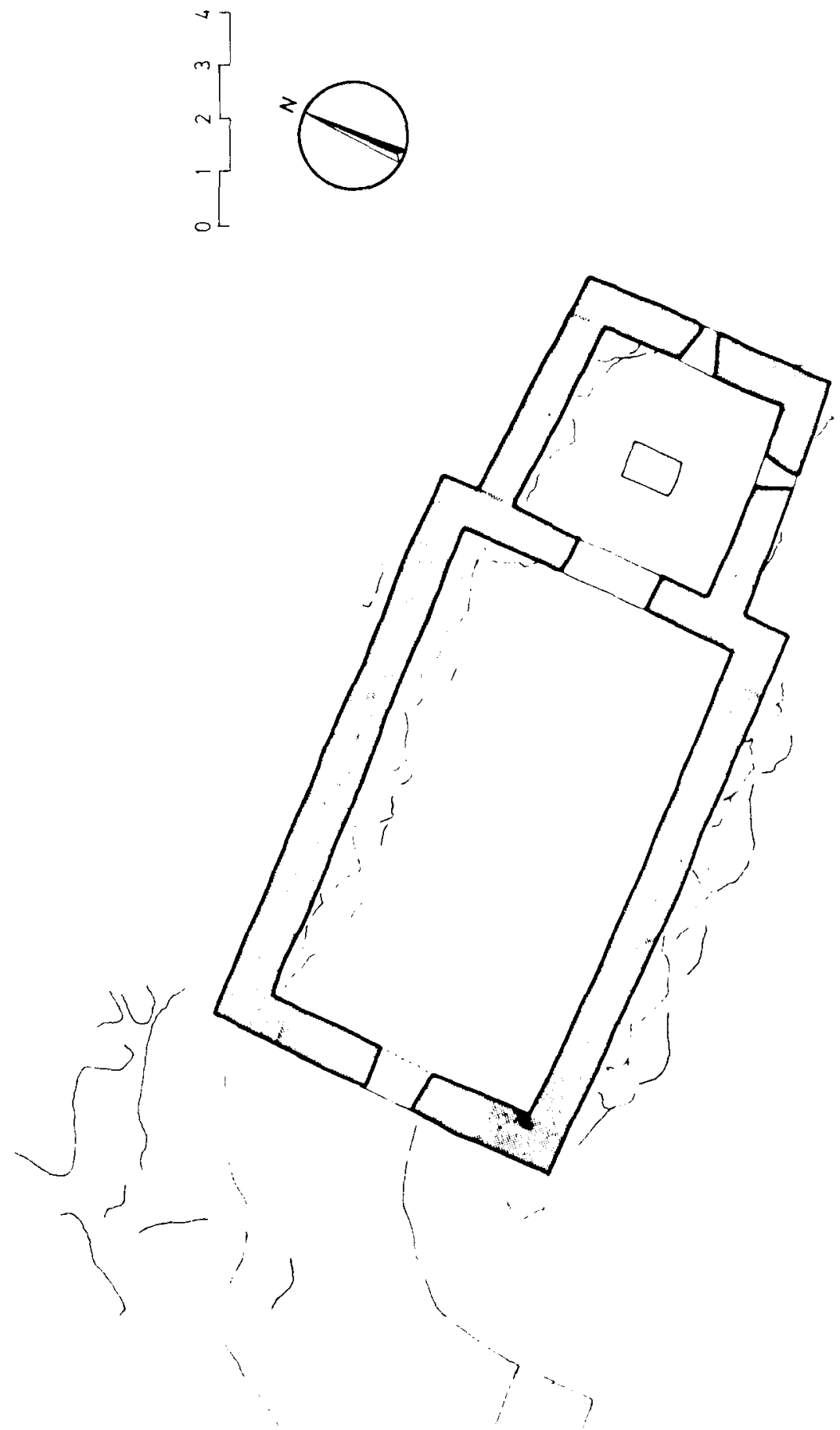

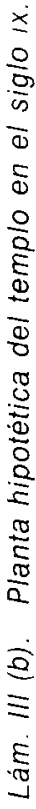


1985: 220), podría ser posterior por haber mutilado las pinturas de finales del siglo xi (cf. 4.3.2). Sin embargo, Gudiol (1937: 112), quien dirigió el arranque de estos frescos, sostiene que es original.

Los elementos de la cubierta no los conocemos directamente, pues las modificaciones sufridas por el edificio a lo largo del tiempo han eliminado todos los lugares donde podia estudiarse su configuración primitiva. Sin embargo, existen algunos indicios elocuentes. En primer lugar, el escaso grosor de las paredes de la nave hace pensar que fueron coronadas por una estructura de madera. En segundo lugar, el espesor mucho mayor de los muros de la cabecera invita a suponer que sostuvieron desde antiguo una bóveda, hoy desaparecida (la actual es del siglo $x$ avanzado, cuando se recreció la cubierta; en aquella época se pintó el intradós por primera vez; cf. 4.2). Por lo que se refiere a la culminación del sistema, sabemos casi con certeza que fue de tejas. La excavación al noroeste del edificio (infra, 4.3) ha proporcionado un relleno con gran numero de tales piezas, cuyo terminus ante quem puede cifrarse hacia el primer cuarto del siglo $\mathrm{xI}$. De este modo, sabemos que al menos la iglesia del siglo $\mathrm{x}$ avanzado contó con una cobertura a base de estos materiales. Teniendo en cuenta que tampoco entonces hubo bóvedas en las naves y que el empleo de tejados responde a una tradición en cierto modo arcaizante, parece lógico suponer que el primer edificio ya debió cubrirse con el mismo procedimiento.

Un nuevo dato arqueológico, proporcionado por la excavación de la cubierta de las cabeceras laterales que permanecian intactas, indica que en las absidiolas de la fase siguiente tampoco debieron emplearse losas pues, a pesar de haberse encontrado sobre el extradós de sus bóvedas un conjunto de rellenos bastante variopinto, como corresponde a lugares sujetos a continuas reparaciones, las únicas piezas que han aparecido in situ, concretamente sobre el ángulo suroeste del cuarto de esfera meridional, son tejas semicilindricas de un tipo muy caracteristico de Pedret. Estas piezas las conocemos bien por haberse descubierto en todos los sectores del yacimiento, en algunas zonas fuera de contexto pero en otras perfectamente estratificadas. Ciñendonos al citado estrato de hacia el primer cuarto del siglo xI localizado en el sondeo noroeste, donde los fragmentos de estas piezas se contaban por millares, debe apuntarse que la mayor parte de las tejas son semicilindricas, de paredes relativamente delgadas y pasta oxidada o de sandwich, roja en los lados y gris en el centro, aunque también han aparecido algunas de pasta gris. Además, los extremos de los lados mayores - los rectilineos - presentan una característica incisión longitudinal en forma de uña. Junto a las piezas semicilindricas, que pudieran haber seguido la tradición de los imbrices romanos, aparecen unos pocos fragmentos de piezas planas, cuyos lados 
Una nueva excavación en la iglesia de Sant Quirze de Pedret ...

mayores también poseen uña y se hallan ligeramente inclinados hacia arriba. Esta morfologia, aunque de lejos, no deja de recordar la de las tegulae.

Como se ha dicho, el único dato cronológico fiable respecto a este material es su t.a.q. del 1000/1025, proporcionado por algunos fragmentos de ollas grises que lo acompañaban (que actualmente tenemos en estudio, junto con el resto de cerámica gris aparecida en el yacimiento), to cual da seguridades para considerar que las tejas se utilizaban desde tiempo atrás, puesto que ya había sido amortizada una buena cantidad. Ello nos proporciona bastantes seguridades sobre su uso en el edificio del siglo $x$. Sin embargo, un somero análisis cuantitativo del material podria dar pie a una nueva hipótesis. Se trata de considerar la presencia de tejas planas reparando en su escaso número. Si tales elementos hubieran coexistido con los semicilindricos durante la etapa del siglo $x$ avanzado, el estrato referido debiera haber albergado una cantidad mucho mayor que incluso hubiera superado con creces la de aquéllos. No siendo asi, es preciso pensar que la iglesia de aquel período sólo tuvo tejas semicirculares o que, al menos, su mayoria era abultada.

¿Dónde situar entonces el pequeño contingente de elementos planos aparecido? Nuestra suposición es que tal vez procediese del templo original, acaso de la cabecera, y que hubiese sido reutilizado en algún lugar de las nuevas cubiertas colocadas en el siglo $x$ avanzado (infra). De este modo, en el xI, sólo quedarian algunos vestigios. En consecuencia, se podria suponer que la iglesia de hacia finales del siglo Ix poseeria un tejado a la romana; es decir, con elementos cuya morfologia recordaba bastante de cerca la de tegulae e imbrices.

El pavimento de esta época tampoco lo conocemos directamente. Sin embargo, en los "diarios" de las primeras excavaciones aparece descrito como de tierra mezclada con cal, siendo la cúspide del primer relleno de arcillas rojizas depositado en el interior del edificio (BATISTA 1960: 8-19; BUCHACA 1960: 32-35, no llegó a identificarlo como tal, pero en las secciones B-A y D-C dibujadas entonces se observa con nitidez), lo que no desdice de lo constatado en unos pequeñisimos testigos conservados al fondo de la nave, bajo un banco corrido moderno. Por otra parte, la reconstrucción de la secuencia que hemos realizado (lám. VIII) indica que presentaba una pendiente ostensible hacia el sur, y que en el lado septentrional algunos tramos de la roca previamente desbastados también se usaron como suelo; otros, los más próximos a la pared norte, a la que servian de cimiento, quedaron simplemente a la vista en su estado natural. 


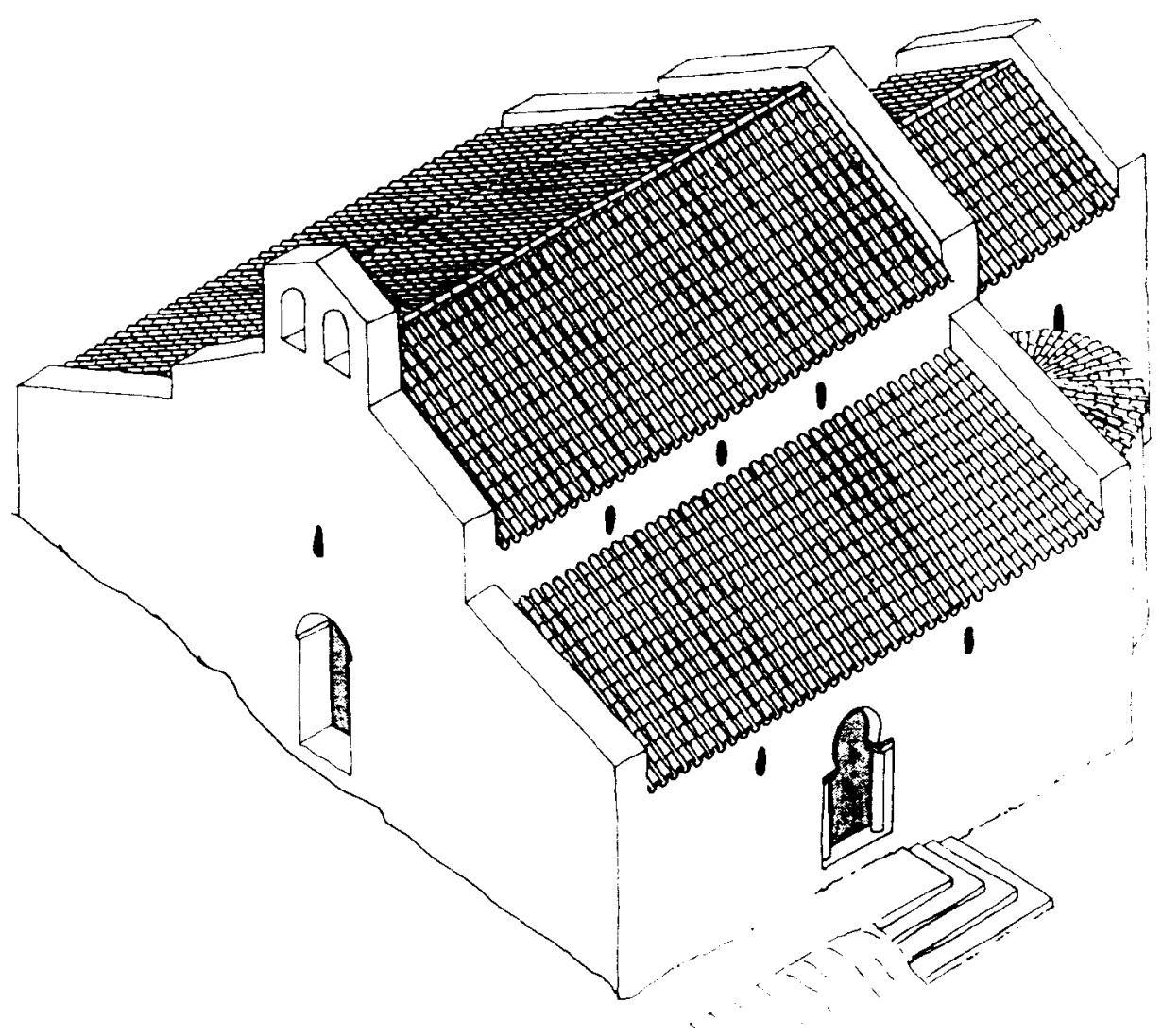

Lám. IV, a. Perspectiva hipotética del templo en el siglo x avanzado. 
Una nueva excavación en la iglesia de Sant Quirze de Pedret ...
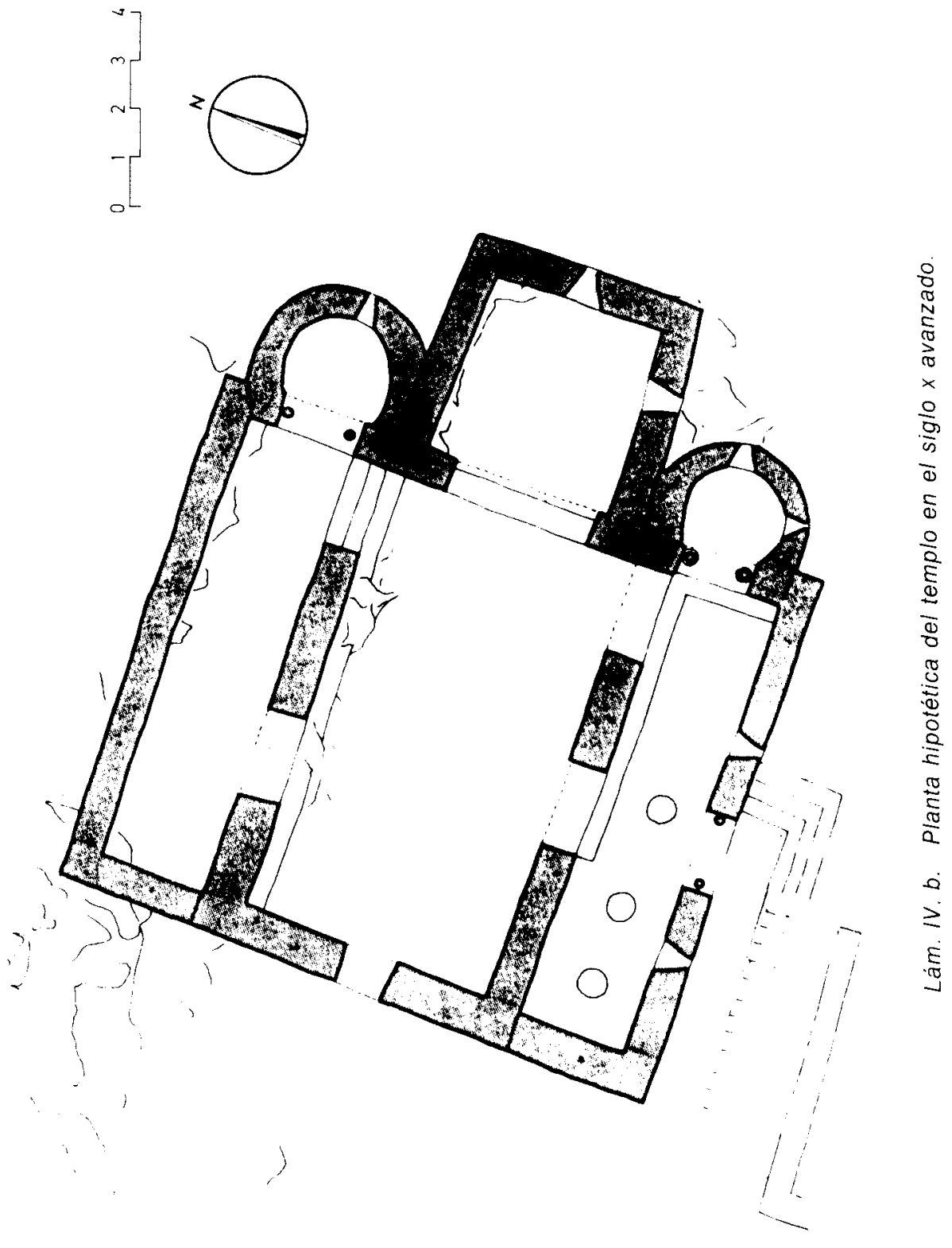
Del pavimento exterior poseemos datos más abundantes. En los alrededores de la cabecera fue la propia roca que, a pesar de presentar una pronunciada pendiente de norte a sur, es bastante lisa. Al lado de la nave norte fue de tierra batida y en el entorno de la fachada sur se constata claramente un suelo ostensiblemente inclinado hacia mediodía, que conserva restos de mortero de cal. Este estrato se identificó perfectamente hace treinta años (Ibidem, 23 ss.) y ahora hemos vuelto a descubrirlo en el testigo del ángulo sudeste del edificio, excavado durante nuestra primera campaña.

De todos modos, la disposición más caracteristica de este pavimento se ha constantado al suroeste del edificio. En este lugar formaba una sucesión de terrazas escalonadas que conducian desde un nivel muy bajo - cercano al de la roca que circunda actualmente la casa al sur de la iglesia- hasta la puerta del templo, situada en el testero occidental. Tan elocuente disposición topográfica confirma una vez más nuestra hipótesis sobre el acceso al templo en esta época. Por otra parte, la considerable masa de tierras que formaban las mencionadas terrazas ha proporcionado un interesante conjunto de cerámicas oxidadas/espatuladas, situables en el último tercio del siglo Ix (lám. X), las cuales datan la fundación del edificio.

Además de las estructuras directamente relacionadas con la arquitectura de la iglesia, el yacimiento ha proporcionado otros vestigios asociables a esta fase. Nos referimos a una serie de tumbas de perímetro elipsoidal recortadas en la roca caliza aprovechando diaclasas las más de las veces. Todas ellas se hallan orientadas de este a oeste, con la cabeza del inhumado a poniente, y siempre presentan una cubierta de grandes losas sin desbastar. En ningún caso han proporcionado ajuar.

En el subsuelo de la nave sur, cerca del ángulo suroeste, apareció una tumba situada debajo de un silo aprovechaba una grieta natural (lám. (X). El individuo se adaptaba completamente al perímetro de la diaclasa, aunque conservaba, al menos teóricamente, la orientación este-oeste. La superposición del silo respecto a la tumba confirma la datación de ambos elementos, pues, al practicarse el depósito de cereal se cortó un primer estrato con cerámica gris característica del siglo $x$ y un segundo, más profundo, con cerámica oxidada de la centuria anterior. Dentro de esta misma capa se halló la inhumación referida. Como elementos caracteristicos de esta etapa, también cabe citar una sepultura cuyos pies se hallaban ligeramente cubiertos por los cimientos de la nave de mediodia, y dos esqueletos infantiles encontrados entre las grietas de la roca al noroeste de la iglesia, sólo cubiertos por algunas losas de caliza. 
En general, el rito de estos enterramientos es bastante descuidado (lám. VIII.2). La cubierta la forman invariablemente lajas de piedra y el aprovechamiento de las diaclasas naturales, según se ha visto en algunos ejemplos, es intensivo. Seguramente este proceder fue debido a la escasez de tierra en los alrededores del templo, cuestión que se solventó en parte durante la fase siguiente al cambiarse de lugar la puerta de la iglesia, lo cual permitió echar nuevos rellenos al oeste y suroeste de la fábrica, lugares que desde entonces y hasta nuestros dias constituyeron el cementerio por excelencia.

Antes de pasar a otras consideraciones, nos gustaria hacer hincapié en la situación de estas sepulturas: todas ellas han sido descubiertas fuera del perimetro que postulamos para la primera fase del edificio; es decir, la cabecera y la nave mayor actuales. Una se encontró dentro de la absidiola de mediodía (BuChACA 1960: 24; nosotros la hemos uredescubierto" durante la primera campaña), otra apareció en el ámbito de la antigua nave sur, cortada por el muro occidental del cuerpo sudeste actual y por un silo (infra, 4.2; 4.4), y una tercera se localizó en las ruinas del añadido de poniente, con los pies materialmente pegados al testero de la iglesia, y la cabeza bajo el muro oeste de la estructura citada (Ibidem, 35 ss.; también “redescubierta» en nuestra excavación).

El estudio de las necrópolis medievales cristianas en Cataluña, ya suficientemente desarrollado (estado de la cuestión en Riu (dir.) 1981-1982; corpus parcial en la serie Catalunya Románica), y al que nuestro Servicio ha contribuido con una dilatada experiencia en la excavación de esta clase de conjuntos (cf. numerosos ejemplos con bibliografia anterior en: $A c-$ tuaciones en el patrimonio edificado medieval y moderno (siglo $x$-xvili). Barcelona 1991), indica que los enterramientos tienden a ocupar los aledaños de las iglesias, concentrándose en la sagrera, y que muy rara vez están en el interior de los edificios religiosos. El caso de Pedret es, pues, un ejemplo entre muchos y resulta igualmente indicativo. De este modo, un nuevo argumento viene a confirmar nuestra suposición inicial respecto a la configuración del primer templo.

Por otra parte, la tipología de las tumbas (sintesis en Bolós, PAGÉs 1981-1982), aunque no es un argumento cronológico exacto, proporciona ciertas precisiones. Está comprobado que las sepulturas antropomorfas corresponden, a grandes rasgos, al siglo $x$, centrándose tal vez en un momento avanzado del mismo. Se sabe también que el contorno elipsoidal de algunas inhumaciones puede ser anterior, aunque su presencia también se registre hasta un momento tardio de la misma centuria ( $v$. gr. LOPEZ Mullor (dir.), 1989). Pese a todo, la falta de tumbas antropomorfas en la primera etapa del cementerio de Pedret, puede hacernos pensar 
que las encontradas son anteriores al desarrollo pleno de aquéllas, y que debieran situarse en un momento temprano del siglo $x$ o quizás antes.

La carencia de material arqueológico estratificado habia determinado que hasta el comienzo de nuestros trabajos no se hubiese desentrañado la cronologia absoluta del primer edificio de Pedret, del que, por otra parte, no se conoce referencia documental alguna (Gómez Moreno 1919: 59, afirma que la iglesia "carece de historia", resulta un tanto radical pero es ilustrativo). Pallás (1962: 63-64) lo hacia visigótico, teniendo en cuenta su similitud con Sant Vicenç d'Obiols, donde se encontró una moneda de Égica (Ibidem, reproducción fotográfica en LACUESTA (coord.), 1986: 70). Aquella pieza parece ser que fue encontrada en el interior de una sepultura - ¿quizás de un sacerdote? - situada fuera de la iglesia, al lado de la puerta. No obstante, al haberse localizado a lo largo de trabajos no arqueológicos, se desconoce su contexto extratigráfico preciso, y aunque algunos investigadores hayan jugado con la posibilidad de un edificio visigótico desaparecido (JUYENT 1983: 134), otros lo descartan resueltamente (RIu, loc. cit., BarRaL 1981: 179; Ibidem). Otros autores creen que el templo de Pedret es más tardio. Sitjes (1977: 118) lo sitúa en el siglo Ix. Junyent (1983: 142) piensa, basándose en modelos tipológicos aplicados a una larga serie de templos, que puede ser de un momento temprano del siglo $x$, siendo la siguiente fase de la misma centuria, pues considera que el aparejo de entonces es muy similar al primitivo.

Sin entrar a discutir las hipótesis de un grupo de investigadores (PUIG I Cadafalch, Falguera, Goday 1909: 366-370; Gómez Moreno 1919: 59-63; Gudiol 1937: 107-113; BarRal 1981: 180-181) que suponen la iglesia inicial de tres naves, lo cual consideramos inviable a la vista de los hallazgos que se han expuesto y los que se explican en el epigrafe siguiente, hemos de concluir que la cronologia de Pallás, muy sugestiva para su época, hoy debe descartarse teniendo en cuenta el abundante material cerámico perfectamente estratificado que poseemos, el cual, a la espera de poder confrontarlo con un mayor número de paralelos (de momento, puede verse: RIBAS, 1967; RIU, M. 1980, 1984, 1986-1987; RIU, E. 1984), situamos provisionalmente en el último tercio del siglo $\mathrm{x}$ o principios del $\mathrm{x}$. Asi las cosas, parece que la hipótesis más atinada de las propuestas en el pasado es la de Junyent, que se aviene perfectamente con lo descubierto ahora y con un paralelo ciertamente ilustrativo, cual es la iglesia de Sant Miquel de Sornià (Ponsich 1983, cf. más datos en 4.2).

\subsection{Segunda fase, ca. mediados siglo x (lám. IV. a y b)}

La configuración del edificio de esta época resulta bastante clara: se trataba de una iglesia de tres naves, la mayor dotada de cabecera tra- 
pezoidal y las colaterales de absidiolas con planta en forma de herradura. Esta misma morfología adoptaban los arcos que coronaban las embocaduras de las tres capillas. En el caso de la mayor, ya no se trataba del arco triunfal de la primera etapa, pues en el momento que nos ocupa se construyó otro algo más ancho con dovelas muy estilizadas e impostas bien marcadas. En cuanto a las absidiolas, las arcadas de las dos eran muy similares entre si, dotadas de dovelas algo más anchas e impostas proporcionalmente más gruesas, en ambos casos apoyadas en columnas de capiteles poligonales con tosca decoración geométrica, fustes lisos y basas troncocónicas simples, de las que sólo se conocen vestigios seguros en la estructura meridional.

Las aulas laterales se comunicaban con la central a través de dos vanos en cada lado, acabados en arcos de herradura casi idénticos al triunfal de la capilla mayor. Los de levante, cuya situación conocemos exactamente, se encontraban a ambos lados de la cabecera principal y seguramente, como interpreta Barral (1981: 180), su colocación responde al interés por sugerir un transepto, siquiera conceptualmente. De los arcos de poniente sólo se conserva uno; el otro es de suponer que ocuparia el lugar de la puerta actual, pues nuestras investigaciones han confirmado que, de existir, no pudo encontrarse en otro sitio.

Debe advertirse que el aparejo utilizado durante este época no difiere demasiado del colocado en el edificio original, aunque, al menos en la fachada de mediodia, la más representativa, presentaba toscas hiladas. Esta similitud, en lineas generales, resulta lógica si se tiene en cuenta que se utilizaron los mismos materiales autóctonos, y que no se habian introducido grandes cambios en las técnicas constructivas. Con todo, la semejanza señalada puede haber contribuido a condicionar las hipótesis de investigadores que no han realizado excavaciones arqueológicas o no han tenido acceso a sus resultados.

Antes de continuar, y como aproximadamente la apariencia descrita hasta aqui es la que tomó el templo después de la primera restauración, la cual se ha visto reflejada en publicaciones posteriores, bueno será advertir que durante aquellas obras se reconstruyó casi por completo (a excepción del arranque de levante) el arco de herradura oriental que comunica el cuerpo sudeste con la nave mayor, ya que su trazado se hizo de medio punto en el siglo xIII (infra, 4.4). En el arco triunfal de la cabecera mayor, modificado en la misma fecha pero no tan radicalmente, se añadieron las impostas y algunas dovelas utilizando materiales nuevos. En cuanto a las embocaduras de las capillas laterales, la del norte se reconstruyó completamente usando materiales originales, que en su mayoria habian aparecido embebidos en el tabique que hubo en el tercio 


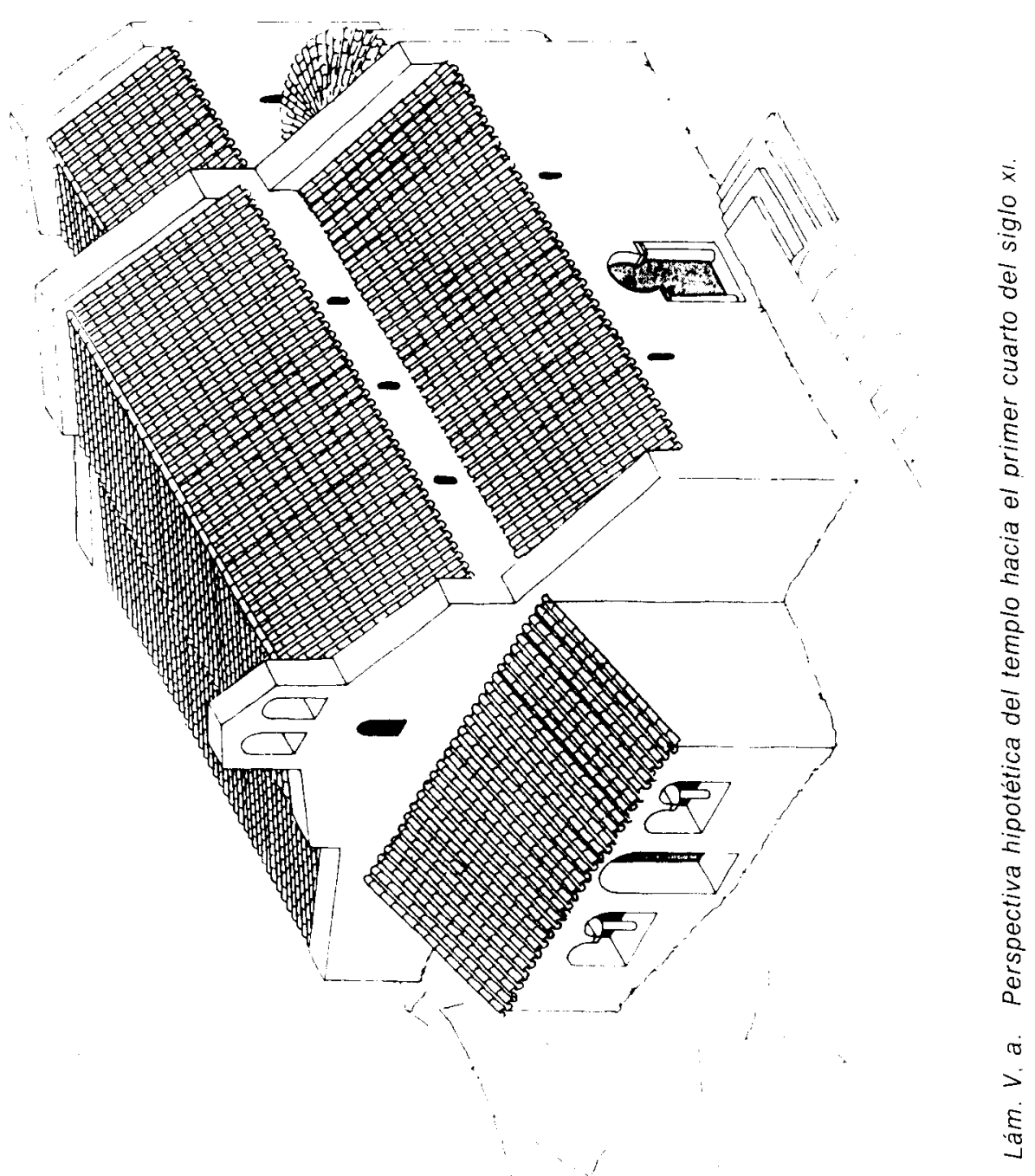




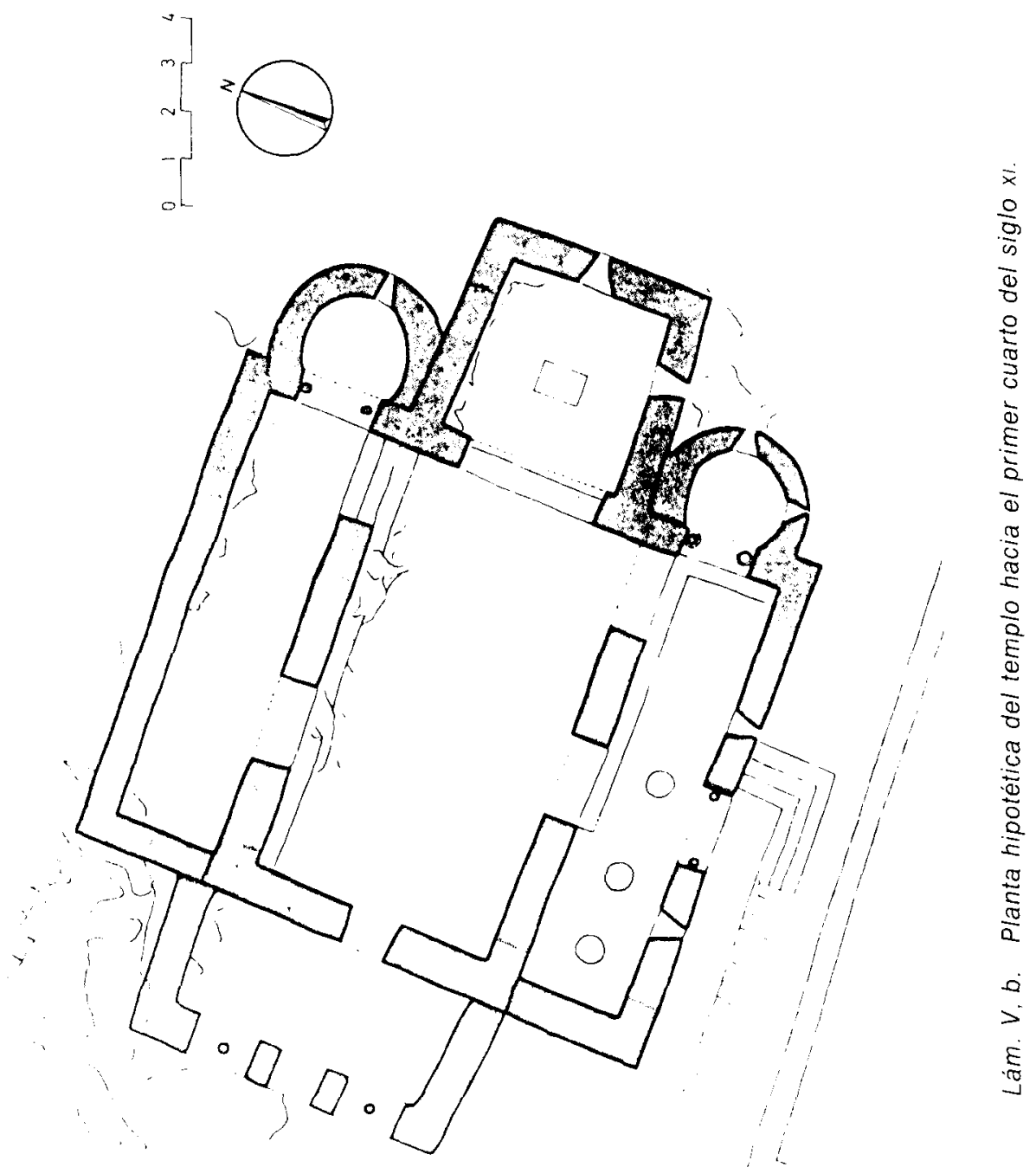


oriental de la nave del mismo lado; además se imitió una imposta de la que se carecia. En la capilla sur se colocó un capitel nuevo y se restituyeron los fustes usando elementos que habian sido reutilizados en otras partes del edificio en la época moderna, completándose sólo pequeños fragmentos (BUCHACA 1960, con fotos y alzados a escala).

Para formar la iglesia de tres naves, los constructores perrománicos adosaron sendos cuerpos de nueva planta al edificio de la fase anterior. El septentrional permanece in situ sin demasiadas modificaciones y del meridional sólo se conserva el tercio de levante, aunque nuestros trabajos han evidenciado el trazado del resto conservado en una altura suficiente, a veces de más de un metro (lám. XIV). Por si la sola observación del edificio no fuese suficiente para constar estos cambios, las excavaciones han proporcionado algunos argumentos ilustrativos. En primer lugar debe citarse la entrega de las ruinas del muro de poniente de la nave sur al paramento meridional del cuerpo primitivo, convertido en nave mayor. Una disposición análoga se puede comprobar en el cierre de la absidiola de mediodia, donde, para mayor claridad, tambièn se ha localizado el ya citado muro de arriostramiento bajo el umbral de su entrada, que vuelve a entregarse a la pared sur del primer templo. En la nave norte se carece de este elemento de trabazón, pues la nueva estructura se apoyó en la roca casi al nivel del pavimento. No obstante, las entregas de todos sus paramentos al cuerpo principal son muy esclarecedoras.

Además de los muros, también se entregaban los estratos. En el cuerpo septentrional no se dio el caso, pues la presencia de la roca virgen a considerable altitud obvió el uso de rellenos. En el meridional, sin embargo, se necesitaba salvar un desnivel de casi un metro entre la antigua cota exterior del edificio y el nuevo suelo de la nave sur. En consecuencia, se depositaron tres capas de relleno, cubriendo la inferior el pavimento exterior citado (supra, 4.1), y lógicamente ambas entregadas al repetido muro meridional del edificio pristino (lám. VIII.1). Dentro de la absidiola de mediodia la estratigrafía era idéntica, cubriendo además el estrato inferior una de las tumbas elipsoidales mencionadas más arriba.

Por si fuera poco, los pavimentos de esta etapa no eran iguales a los de la anterior, que permanecieron en uso. En la excavación de las absidiolas y las naves colaterales se ha documentado un nuevo suelo de losas calizas colocadas en seco, apoyadas sobre el segundo de los rellenos aludidos en el párrafo anterior (esta situación se da al sur; al norte, la potencia era más escasa y el suelo casi carecia de preparación). Estos suelos coexistieron con el de tierra batida y cal de la nave mayor, procedente de la iglesia primitiva, según demuestran las estratigrafias practicadas en este lugar (BATista 1960: 6-12; BuchacA 1960: 23, 33, 35,39-40). 
Es más, la propia capilla mayor conservó el sencillo pavimento de tierra apisonada que tenía en el primer momento. Otro dato que debe tenerse en cuenta es la presencia del nuevo suelo de losas sobre el arrasamiento del muro lateral sur de la nave principal, rebajado irregularmente cuando se abrió la comunicación con la nave lateral de mediodia.

Tan evidentes como las entregas de los nuevos cuerpos al preexistente son los recrecidos de la nave mayor y su cabecera. Este proceso dejó una muestra ostensible en los paramentos laterales del edificio actual. En el de mediodia se puede advertir sin dificultad, contemplando la fachada de ese lado; donde aparece un marcado escalonamiento. El recrecido de los muros propició, además, la apertura de una serie de nuevas ventanas, todas ellas de derrame único: tres simples al sur, en la fachada descrita, y una geminada al este, sobre el testero oriental, que también se recreció entonces. En el eje de las absidiolas de nueva planta se abrieron sendas ventanas de morfología similar; la del lado norte fue modificada posteriormente (infra, 4.4) y una segunda ventana, abierta al sur de la cabecera meridional, es obra posterior (pues cortó las pinturas de finales del siglo $\times 1$ ). Por supuesto, siguieron en uso las aberturas que ya tenia la cabecera mayor

Aunque ya hemos tratado sobre el pavimento de esta época al destacar la diacronia de los añadidos respecto a la obra primitiva, es conveniente volver a la apariencia interior del templo, antes de pasar a las caracteristicas del entorno. Quizá, el hecho más destacable sea el considerable desnivel que presentaba la nave norte en relación a las otras dos, pues para acceder a ella desde la central era necesario salvar cuatro escalones. Una disposición de esta indole podria ser interpretada a partir de necesidades litúrgicas, pensando que en tal espacio podria haber albergado un hipotético coro (GuDIOL 1937: 112) pero, como luego veremos, no hay seguridad sobre la utilización del rito hispánico en este área durante el siglo $x$. De todos modos, lo que conocemos de este ordenamiento cultural sugiere que el coro, en caso de tener entidad arquitectónica, no deberia encontrarse en una posición tan excéntrica (cf. p. ej.: RodRiguez de Ceballos 1965: 317; Puertas 1975: 100). También se ha barajado la posibilidad de que el templo de Pedret fuera durante aquellos años el de un monasterio (SITJES 1977: 113), lo cual no es imposible, según observaremos. Sin embargo, los escasos paralelos de construcciones de este tipo que conocemos en nuestra área geográfica no presentan elementos asimilables, al menos en este periodo.

Por último, cabe la posibilidad de interpretar esta disparidad de niveles ateniéndose a las propias características del yacimiento. Antes hemos hecho hincapié en el pronunciado desnivel que presentaba la ladera de 


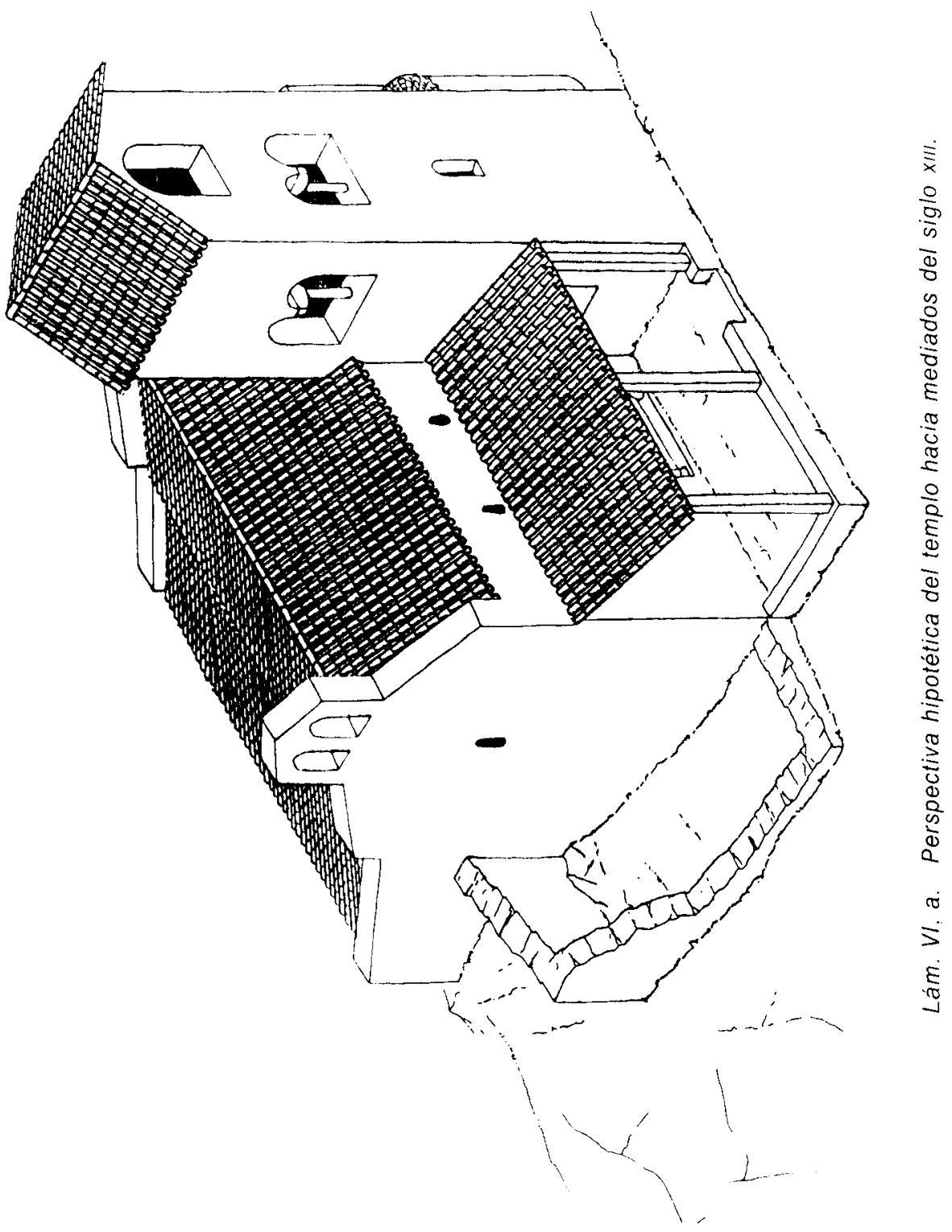


Una nueva excavación en la iglesia de Sant Quirze de Pedret ...
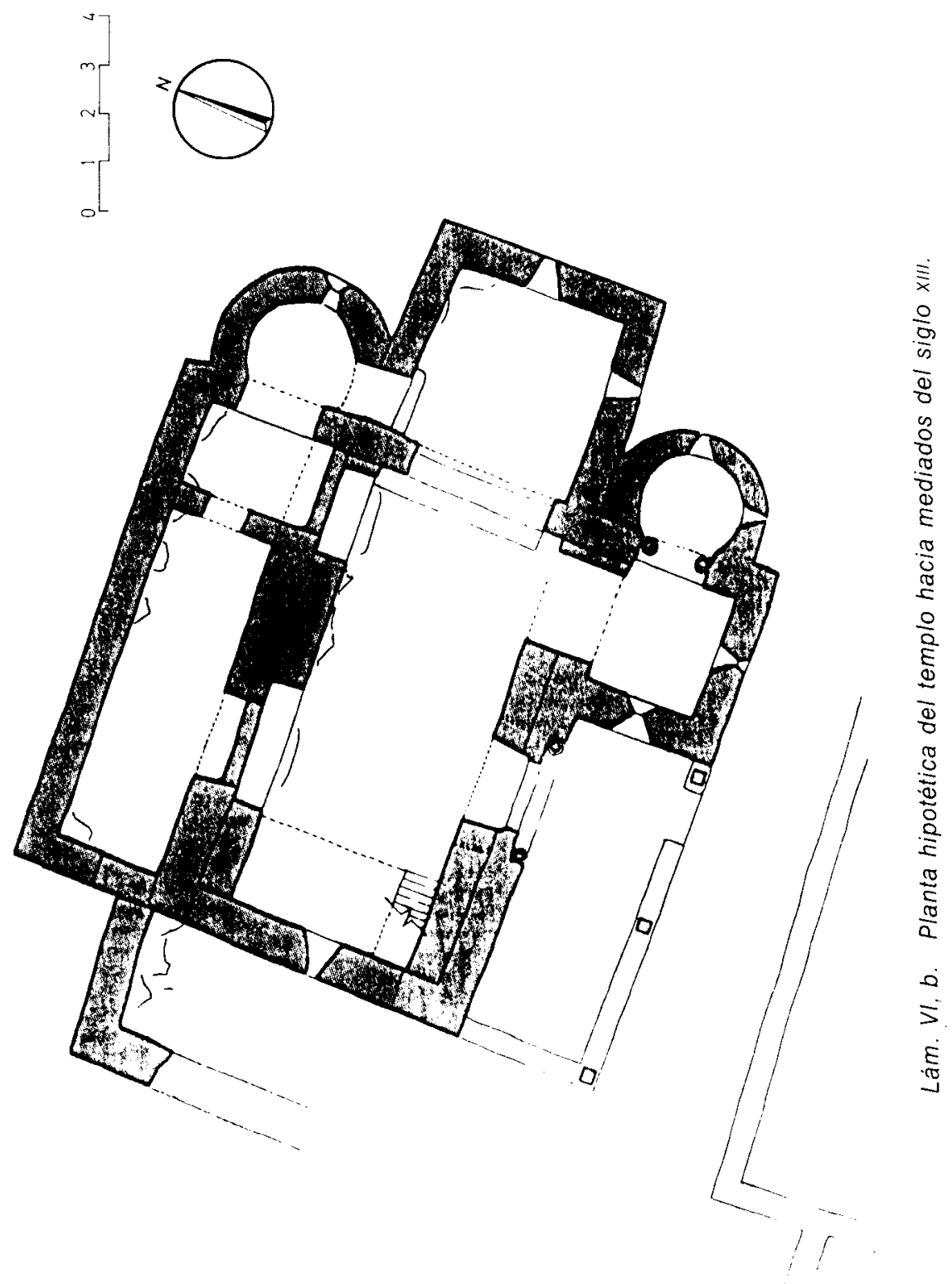
la montaña donde se edificó la iglesia. Este desnivel no afectó demasiado a) aspecto interior del primer templo de nave única, aunque es notorio que en su lado norte afloraba la roca natural por encima del resto del pavimento. En esta segunda etapa, al plantear la ampliación de la iglesia mediante el añadido de naves laterales y no querer, o no poder, edificarla en otro lugar, es lógico que los nuevos elementos hubieran de amoldarse al terreno. En el lado meridional fue relativamente fácil, pues sólo se necesitó depositar una serie de rellenos y reforzar la estructura transversalmente (recuérdese la riostra debajo de la embocadura de la absidiola). En el septentrional, la operación fue igualmente sencilla, ya que bastó colocar los muros sobre la roca, someramente desbastada en ciertos puntos. Sin embargo, debió admitirse la existencia del desnivel interno que nos preocupa.

Respecto a los pormenores del resto de la apariencia interior del templo, nuestra información es migrada. De cualquier modo, se ha podido determinar la posición de la estructura de piedra que sostuvo la mesa del altar, centrada en la cabecera mayor (al desmontarla, se encontraron dos lipsanotecas, GuDIOL 1937: 111, 113; VIGUÉ 1985: 216; el primer autor pensaba que se trataba de un altar moderno, pero la excavación de los años sesenta demostró que, al menos la base, era original). Por el contrario, en las absidiolas no se hallaron vestigios de altares. Como en la etapa anterior, sería presumible la presencia de un poyo para uso de los fieles, adosado a la pared sur de la nave principal. No obstante, el regruesamiento de este muro, acaecido en el siglo xıI, y el posterior derribo de tal añadido hace treinta años, desfiguraron de tal modo el hipotético banco que actualmente resulta muy problemático delimitarlo. En la pared norte, la situación es muy similar, aunque una vez eliminadas las estructuras posteriores, en 1960, no parece haber trazas de asiento alguno.

Un elemento de primer orden para realzar el aspecto interno de la iglesia debió ser el conjunto de pinturas murales que la ornaron, cuya cronologia, aunque discutida, parece poder situarse a mediados del siglo $x$ o algo más tarde. Los restos conocidos se encontraron en la cabecera mayor y en el muro norte de la nave principal, conservándose actualmente en el Museo Dicocesano y Comarcal de Solsona. Tales pinturas han sido objeto de diversos estudios (estado de la cuestión: RosSELL 1985; aportación posterior: WATSON 1990) y son suficientemente conocidas, por lo cual nos excusamos de volver sobre ellas; únicamente las utilizaremos como elemento instrumental en el párrafo destinado a perfilar la cronologia de esta fase.

Teniendo en cuenta el escaso grosor de los paramentos utilizados en la construcción de los elementos nuevos, es lógico pensar que el sistema 
de cubierta con armazón de madera, supuesto en la etapa anterior, volvió a emplearse en ésta. Sin embargo, ahora contamos con un argumento más firme. Nos referimos a los encajes de las cabezas de las vigas localizados en 1960 (Buchaca 1960: foto 13), los cuales aparecieron en el extremo oriental del muro sur de la nave mayor. Este hallazgo hace buena la hipótesis ya apuntada por Puig i Cadafalch, Falguera y Goday, incluso ilustrada con un dibujo (1909, fig. 409). No obstante, a la vista de la posición de estos testimonios, diferimos del detalle de aquella interpretación. De lo que ningún investigador ha tratado hasta ahora, no sólo en ésta sino en casi ninguna otra iglesia, es de los elementos que culminarian el sistema de cerchas. Felizmente, el hallazgo de un estrato intacto conteniendo gran número de tejas, realizado en el sondeo al noroeste de la fábrica, resuelve tal incógnita (cf.: 4.2.1). Al explicar la etapa anterior, ya hemos dado pormenores sobre el particular, y a ellos nos remitimos.

Lógicamente, la cubierta de las absidiolas fue de otro tipo. Sus muros, de mayor medida que los de las naves, permitieron colocar sendas bóvedas de apariencia próxima al cuarto de esfera, una de las cuales, la del lado sur, se ha conservado prácticamente intacta. La del norte, en cambio, fue reparada en época medieval (infra, 4.3). Sobre ambas bóvedas se depositó un poco potente relleno de tierras $\mathrm{y}$, a continuación, el entramado de tejas, según ha demostrado la excavación.

Fuera del edificio, nuestros trabajos han puesto de manifiesto una muy interesante serie de vestigios relacionables con esta fase, conservados intactos al haber tenido escasa incidencia en este área las actuaciones de 1960. Empezando por las proximidades del perimetro sur actual, lo primero que debe mencionarse es el hallazgo de la cimentación completa del tramo desaparecido de la nave meridional (PALLÁS 1962: 65, la dio por encontrada aunque las excavaciones de entonces sólo la afectaron marginalmente). Su conservación es desigual, puesto que las tumbas de los siglos XVI al XIX eran muy abundantes en este sector, y su extraordinaria densidad ocasionó la perturbación parcial de la estratigrafia. De todos modos, el único punto donde las sepulturas hicieron mella irreparablemente fue el ángulo suroeste; el resto del trazado se distingue con nitidez y conserva una medida de tres a seis hiladas (láms. II, XIV). Los rellenos inferiores relacionados con este elemento también se han conservado relativamente bien; no asi los superiores y el pavimento, alterados por los enterramientos modernos. De todos modos, esta parte de la estratigrafia era fácilmente comprobable en el interior del cuerpo sudeste del edificio actual, donde permaneció intacta. 
ALBERTO LÓPEZ MULLOR Y ALVAR CAIXAL MATA

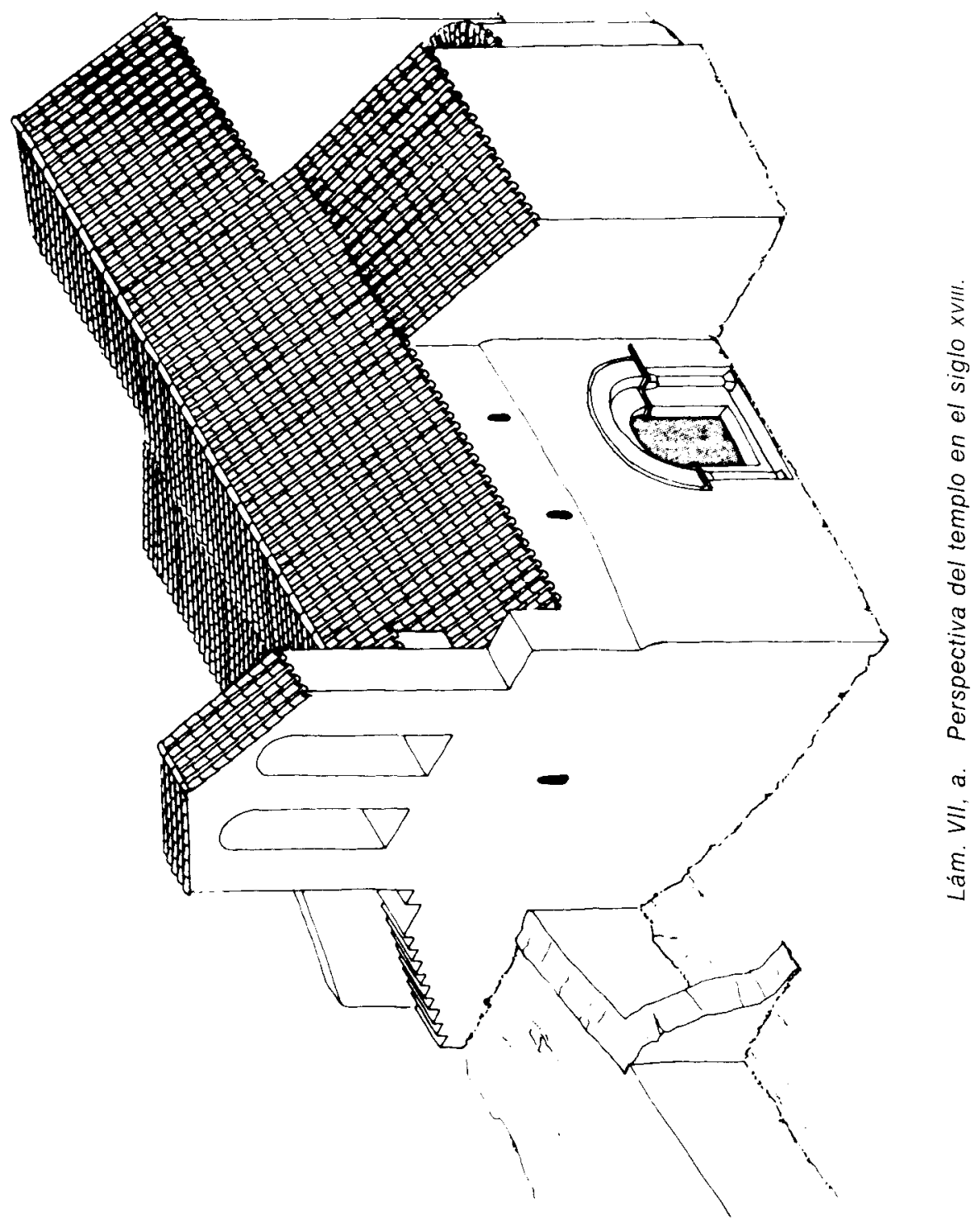



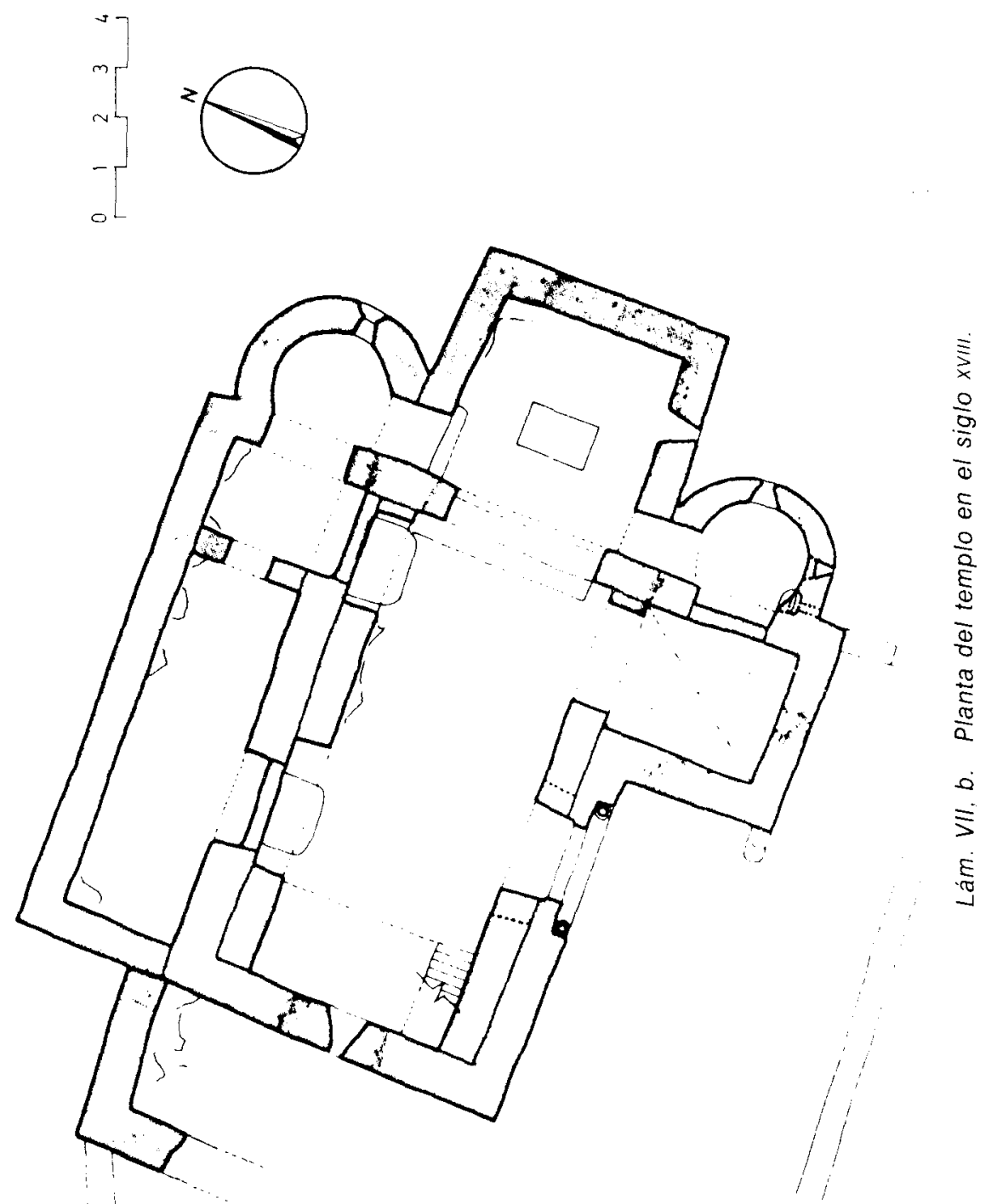
No está de más insistir en la limpia entrega del muro occidental de este espacio contra la esquina del testero occidental de la iglesia de la primera fase. Al tiempo, es necesario reseñar que la trinchera de fundación de la pared de poniente del cuerpo sudeste actual cortaba los estratos del periodo que nos ocupa, terminando en el terreno natural. Siempre dentro del perimetro del trozo de la nave desaparecida, cabe destacar el hallazgo de una sucesión de tres silos, alineados de este a oeste en el centro de la misma. Las sepulturas modernas también menoscabaron su integridad. No obstante, la mitad norte del más oriental ha permanecido razonablemente intacta, al estar protegida por el escalón que precede al umbral de la puerta actual; gracias a ello, sabemos que los depósitos de grano eran fusiformes, y la cota de sus bocas coincidia con la del pavimento del siglo $x$ avanzado (lám. VIII.1). Esta circunstancia nos da un primer indicio para fijar su data fundacional, que se perfila todavia más al tener en cuenta que el primer depósito (situado más al este) cortó una tumba de la primera etapa (cf. supra). En el tercero, construido en gran parte con ripios formando toscas hiladas, la situación es similar porque también cortaba estratos de la fase anterior y, después de excavarlo, se comprobó que debajo suyo subyacia otra sepultura (lbidem). Todo ello nos hace concluir que los depósitos son posteriores a la primera etapa y aún algo tardios dentro de la segunda, ya que su boca respetó la cota del pavimento de aquel momento pero su perfil cortó los rellenos depositados entonces. De este modo, obtenemos para tales estructuras un terminus post quem de hacia mediados del siglo $x$.

La situación de los silos, dentro de la iglesia, resulta de lo más ortodoxo, y se ha comprobado en multitud de yacimientos catalanes (entre otros: Sant Marçal de Terrassola, Sant Bartomeu de Navarcles, Sant Quirze de Muntanyola, Santa Magdalena de Pont de Vilomara y Santa Margarida de Martorell; bibliografia en el simposio Actuaciones en el patrimonio edificado medieval y moderno [siglos $x$-xvII]. Barcelona 1991). Sirvieron generalmente para guardar el diezmo, y su uso más intenso se comprueba desde el siglo xI hasta el XVIII, cronologia de la mayoria de los yacimientos mejor conocidos. De todos modos, debieron emplearse antes, según se desprende de alguno de los paralelos citados. En cuarito al abandono temprano constatado en Pedret (siglo XIII, cf. 4.4), no cabe tenerlo en cuenta para establecer principios genéricos, por responder a causas accidentales.

Fuera del perímetro del templo del siglo $x$ avanzado, pero en el propio entorno de la fachada sur actual, se han producido otros hallazgos reseñables. En este caso dan nuevas precisiones sobre la apariencia de los alrededores del edificio en aquella época y también explican el funcionamiento de uno de sus elementos desaparecidos: la puerta meridional. 
Una nueva excavación en la iglesia de Sant Quirze de Pedret ...

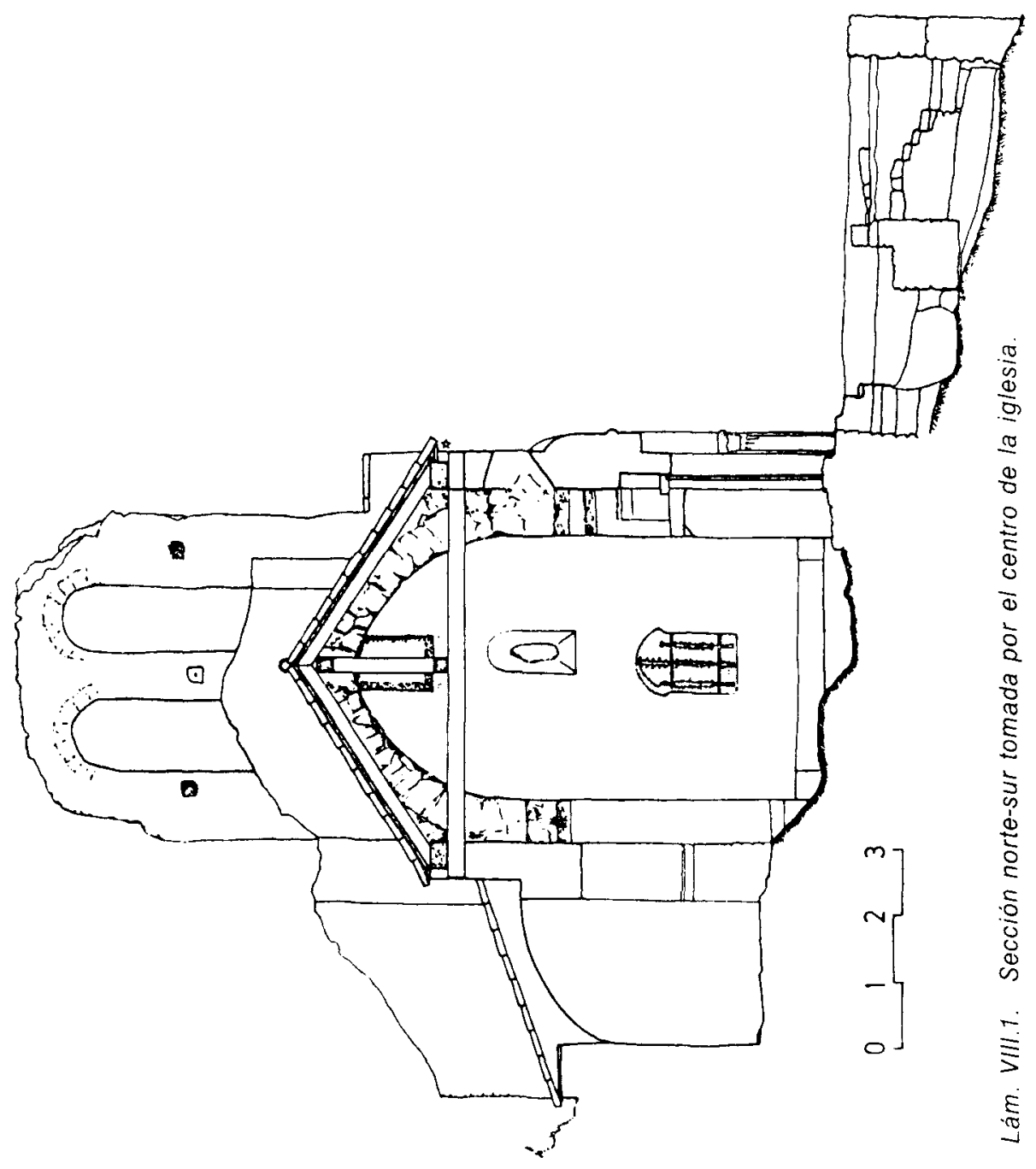




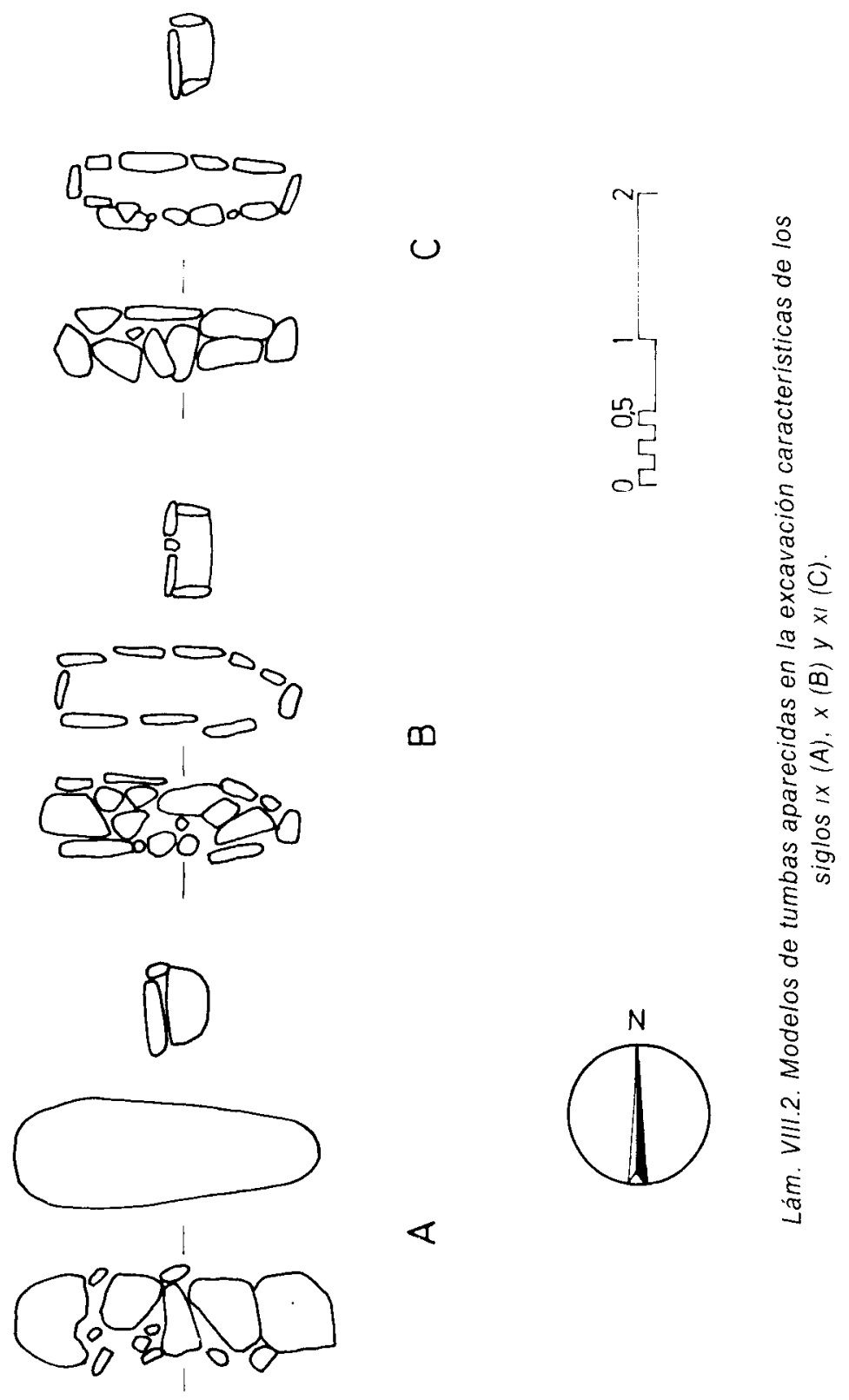


La estructura que sirve para establecer ambas cuestiones es una plataforma escalonada, adosada a los restos de la fachada de mediodia. Comprende una superficie horizontal, encarada aproximadamente con la puerta románica y una serie de gradas en dirección este y sur (láms. II, IV, VIII.1). La superficie horizontal nos hace comprender dónde debió estar el umbral del acceso mencionado; las gradas salvaban el desnivel del terreno natural, tantas veces aludido.

Respecto a la puerta propiamente dicha, era dificil adivinar su aspecto pues nada se conservaba en ella in situ, a no ser parte del umbral. Sin embargo, en el relleno que amortizaba la plataforma descrita (colocado en el siglo XIII, infra, 4.4), se han encontrado dos capiteles prismáticos, dos impostas y diversos fragmentos de fuste, todo ello muy similar a los elementos del mismo tipo empleados en los arcos triunfales de las absidiolas. Asi las cosas, se puede pensar que debieron pertenecer a la puerta que nos ocupa, el aspecto de la cual sería semejante al de las entradas de los ábsides laterales.

En el sondeo efectuado al noroeste de la fábrica, del cual ya hemos dado ciertas precisiones, apareció otra estructura situable en estos años. Se trataba de las ruinas de un muro en dirección este-oeste, que se entregaba a la esquina septentrional del testero de la nave norte. Este paramento, que se prolongaba hacia occidente un trecho relativamente largo, formaba ángulo recto con otro, trazado en dirección norte-sur, del que sólo queda un breve tramo, algo más allá del cierre del añadido de poniente que presenta el edificio actual (láms. II, IV.1).

Por ahora ignoramos la planta completa de esta estructura, y su arrasamiento casi extremo no permite demasiados alardes. Con todo, sabemos que su uso debe situarse entre un momento posterior al inicio de esta fase y el principio de la siguiente. Es decir, entre mediados del siglo $x$ y el primer cuarto del siglo $\mathrm{xl}$, aproximadamente. Ello se deduce de su entrega al testero septentrional del edificio de tres naves, y de haber sido amortizada por el estrato de fundación del cuerpo añadido descrito. Asi las cosas, no es sencillo hipotetizar sobre la función del recinto limitado por estas paredes. Cabe la posibilidad de imaginarlo un antecedente del añadido oeste, que nosotros suponemos un pórtico (cf. fase siguiente), y, suponiendo que su perimetro pudiese reconstruirse idealmente adosado a todo lo ancho del testero, pudiera pensarse en un predecesor del edificio construido en el sur del templo. Con todo, al no haber concluido la excavación, creemos que cualquiera de estas suposiciones es prematura.

Para terminar con la descripción e interpretación de los hallazgos, debe mencionarse la presencia de un buen número de tumbas de esta 
etapa al oeste y suroeste de la fábrica (láms. II, VIII.2). Todas ellas fue posible depositarlas al echarse rellenos en esta zona, convirtiendo en rampa las terrazas escalonadas del momento anterior. Entre las inhumaciones no aparecen sepulturas antropomorfas propiamente dichas (aunque tampoco hay ninguna recortada en la roca), adoptando todas ellas la disposición de cistas rudimentarias, con cabecera diferenciada; la cubierta y los laterales son siempre de lajas de piedra.

La datación de esta etapa del yacimiento se ha deducido tradicionalmente a partir de dos clases de evidencias. Por una parte, el análisis de las pinturas prerrománicas, situadas a mediados del siglo $\times 0$ algo más tarde (WATSON 1990, disiente llevándolas al primer cuarto del xI, por la tipologia del yelmo del caballero, pero este argumento ya fue analizado hace tiempo, reafirmándose la data tradicional, cf. SITJES 1977: 220; BARRAL 1981: 128). Por otra parte, una cita textual que alude a una iglesia en el lugar Pedret, sin mencionar su advocación. Esta referencia figura en el acta de consagración de la iglesia parroquial de Sant Miquel del monasterio de Sant Llorenç prop Bagà, fechada en el 984 (SALLÉS 1985: 291). El primer dato nos parece sumamente útil, aunque revestido de la lógica imprecisión que implica el estudio de un estilo conocido parcialmente y de una iconografia falta de repertorios extensos. No hay duda que las pinturas adornaron el edificio descrito y que, además, fueron sustituidas por otras más complejas en una fecha relativamente temprana (infra). Sin embargo, sólo se colocaron en la nave y la cabecera principales, lo cual es un argumento "estratigráfico" para dar un terminus ante quem de estos elementos y no del resto. La escasa información proporcionada por las fuentes se comenta por si misma. No se menciona la advocación de la iglesia y, en todo caso, se dice que existia en el 984 . Es un punto de referencia, pero prueba bien poca cosa.

Por lo que se refiere a los paralelos, quisiéramos empezar mencionando uno que nos parece de gran utilidad: la iglesia de Sant Miquel de Sornià, cuyos dos cuerpos presentan claras concomitancias con las construcciones de las dos primeras etapas de Pedret (PONSICH 1983). El septentrional es parecido a nuestra nave mayor, y por ello al templo de la primera fase, y el meridional a nuestras construcciones colaterales de la segunda etapa. Sabiendo que el cuerpo sur de Sornià debió construirse poco después del 968 (lbidem), tenemos un terminus ante quem para nuestra primera fase y una referencia aproximada para el momento de edificación de la segunda.

Aparte de este ejemplo, los estudios sobre modelos tipológicos pueden servir de cierta ayuda. Diversos autores están de acuerdo en asegurar que las cabeceras en forma de herradura corresponden al siglo $x$ 
avanzado (v.gr. BARRAL 1981: 84-85; JUNYENT 1983: 195, 197, 201-202, 206207, 229; PONSICH, 1983). La morfologia de los arcos de nuestro segundo momento también se ha estudiado, y coincide cronológicamente con los demás argumentos (BARRAL 1981: 94-95). Todo ello nos hace reafirmar la cronología propuesta que, a grandes rasgos, se sitúa a mediados del siglo x pero podria llevarse perfectamente al tercer cuarto. Quizá la fecha pueda delimitarse algo más mediante el estudio del material aparecido hasta ahora en nuestra excavación. De momento, el único paralelo seguro que conocemos para la cerámica gris ciertamente caracteristica que encontramos (lám. X) procede de la iglesia de Sant Vicenç de Rus. Alli aparecieron estas mismas piezas en el estrato fundacional (LOPEZ MULLOR (dir), 1989, lám. 20.1-5, 7-12, 14), cuyo terminus ante quem viene determinado por un documento del 983 , en el que se menciona el templo (aunque el nombre del lugar aparece desde el 961). De este modo, la tipologia vuelve a indicarnos una data de mediados del siglo $\times$ o ligeramente posterior.

Para terminar con el largo recorrido realizado por esta fase (justificable, a nuestro entender, porque refleja en lineas generales la imagen actual del edificio), quisiéramos entrar en el tema de la función de la iglesia. Su ausencia en documentos donde aparecen relaciones de parroquias (p.e. el acta de consagración de la catedral de Urgell) e incluso la iconografia de un panel de las pinturas románicas, donde se representa la parábola de las virgenes necias y las prudentes (análisis en YARZA 1985: 229-232), ha hecho plantear la posibilidad de que en realidad se tratase del templo de un monasterio, acaso femenino (MUNS 1887; SITJES 1977; BARRAL 1981). Remotamente, esta hipótesis también se podria apoyar en la inusual disposición de la nave norte. Además, poseemos las ruinas de la construcción rectangular situada a mediodia de la iglesia, en la terraza inmediatamente inferior, de cronología posterior (pertenece a la etapa siguiente), pero sobre cuya función será bueno detenerse ahora.

La ausencia de Sant Quirze de Pedret en los documentos contemporáneos puede ser casual. Sin embargo, resulta raro que un templo relativamente grande y al parecer bien dotado pasase tan desapercibido. La iconografia de las pinturas no nos parece relevante, aunque podria completar otros argumentos. Sobre la nave norte y su función coral ya hemos tratado, pero cabe añadir que, según Mundó (1971: 35), el paso a la liturgia franco-romana tiene lugar en Cataluña desde principios del siglo IX. aun siendo un proceso lento que a finales de la misma centuria todavia no ha concluido (Ibidem, 38). Por otra parte, parece que desde el concilio de Aquisgrán (816) las comunidades monásticas de nueva creación adoptan la regla benedictina (PLAdeVall 1989: 27). Ambos datos pueden explicar la ausencia manifiesta de los espacios caracteristicos de las iglesias 
propiamente mozárabes, preparadas para el rito hispánico, pero tampoco son válidos para explicar la presencia monacal o para atribuir sin paliativos una función a dicha nave en la liturgia comunitaria.

El único indicio plausible, a nuestro juicio, es la presencia del edificio rectangular al sur de la iglesia (lám. XII.1), cuya cronología, según nuestra excavación, debe situarse hacia el 1000/1025 (infra). ¿Qué función pudo desarrollar esta edificación? No conocemos sacristias, ni mucho menos casas rectorales, de semejante fuste a principios del siglo xI, por lo cual resulta prudente hipotetizar sobre su uso comunitario. Además, el único documento de estos años que menciona una iglesia en Pedret (sin explicitar advocación) lo hace para indicar la donación de la misma al monasterio de Sant Llorenç prop Bagà. En aquel conjunto, que conocemos bien por haberlo excavado y estudiado a fondo (LóPEz MULLoR 1991; LOPEZ MULloR, CaIXAL 1991, ambos con bibliografía anterior), los edificios de finales del siglo $x$ y principios del $x \mid$ poseen un aparejo idéntico al de las estructuras que analizamos. Todo ello nos hace proponer la hipótesis de la dependencia de Pedret respecto a Sant Llorenç, por lo menos durante el siglo $x$ y seguramente el $x \mathrm{x}$, con la posible instalación en el lugar de una pequeña comunidad. Esta situación podria haber cambiado en 1248, cuando sabemos que la iglesia es parroquia (SALLÉs 1985: 211), y los dominios de Sant Llorenç se encuentran en recesión.

\subsection{Tercera fase, siglo xı (lám. V, a y b)}

\subsubsection{Arquitectura}

Suponemos que durante este período se construyó el añadido de planta aproximadamente cuadrada conservado en ruinas a poniente del edificio. Hasta el momento, carecíamos de datos concretos para tal atribución cronológica, pues esta estructura fue vaciada durante trabajos precedentes (BUCHACA 1960: 32, 35-37). De todos modos, era notorio que su aparejo no se correspondia con el usado en las partes prerrománicas del edificio: se trata de sillarejo bastante bien escuadrado, colocado aproximadamente a soga y tizón y unido con mortero de cal. No obstante, es idéntico a las fábricas reutilizadas en la masia cercana a la iglesia, citada en el párrafo anterior. Esta disposición también recuerda, por cierto, los paramentos de la basilica de Sant Llorenç prop Bagà, erigida hacia el año 1000, y los de sus absidiolas, algo más tardias (de hacia el segundo cuarto del siglo xl).

Por fortuna, un sondeo realizado durante la segunda campaña, entre el muro septentrional de este cuerpo y el cierre de poniente de la nave norte (lám. II), nos ha proporcionado una data bastante precisa para la fundación de la estructura. La estratigrafía de este lugar era la siguiente: 
Una nueva excavación en la iglesia de Sant Quirze de Pedret ...

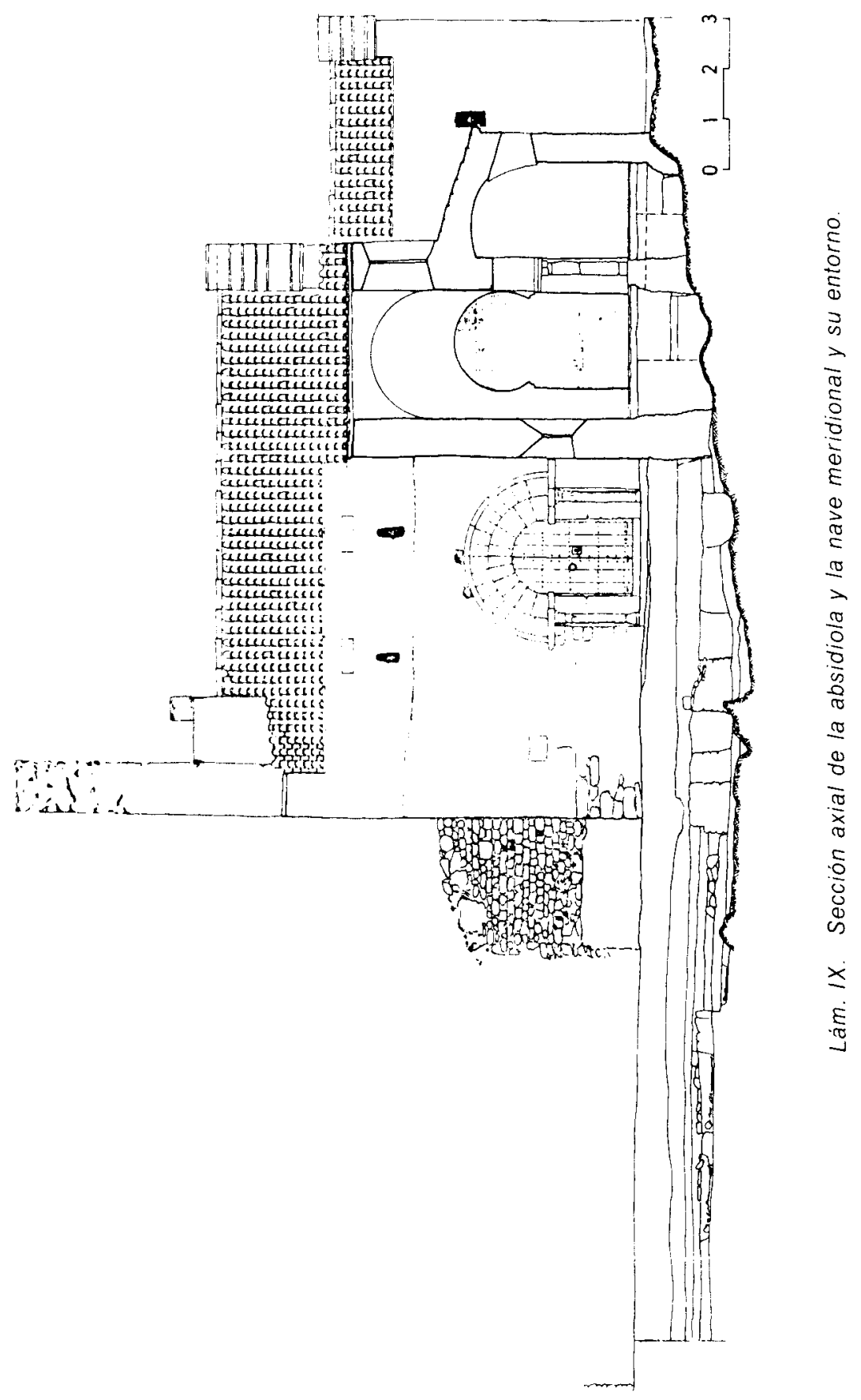


una capa superficial, utilizada como suelo exterior de la iglesia desde el siglo xvIII, un relleno muy potente, depositado en la misma fecha entregándose a las dos paredes citadas, y un pavimento de tierra batida provisto de preparación de arcillas. El pavimento cubria la banqueta de cimentación del muro norte del cuerpo que nos interesa y su preparación dio gran cantidad de tejas, como se ha explicado en epigrafes anteriores. No obstante, estos materiales estaban acompañados de algunos fragmentos de cerámica gris propia del primer cuarto del siglo xI. A continuación se hallaron estructuras más antiguas, de las que ya nos hemos ocupado.

La amortización del elemento no está tan clara porque nuestra excavación del interior se limitó a constatar que habia sido vaciado y vuelto a llenar hace treinta años. Sin embargo, el "diario» de aquellos trabajos, que se realizaron mediante ocho sondeos distintos, da una idea de la estratigrafia alli depositada (Ibidem). Parece que, tras un nivel superficial de aportación, apareció una capa de derrumbe, compuesta por numerosas piedras y tierra, las cuales cubrian todos los muros arruinados menos el septentrional, entregándose a este último y al testero de la iglesia. Debajo, se halló un pavimento de mortero de cal y piedras pequeñas entregado a todas las paredes perimetrales, y a continuación una capa de preparación que trataba de regularizar, sin conseguirlo demasiado, la considerable pendiente del terreno natural en dirección norte-sur. Debe destacarse que, en el lado meridional, apareció una tumba de inhumación, cubierta por los cimientos del muro occidental, de la cual ya hemos tratado al ocuparnos de la primera etapa del yacimiento.

En líneas generales, es muy dificil identificar el material que apareció en estos trabajos, aunque en el Museo Municipal de Berga se hallan expuestas algunas piezas significativas aludidas en el "diario", tales como fragmentos de vidrio y sobre todo un vaso cerámico vidriado y decorado (publicado en Bolos, RIu, C. 1985). Tanto estos objetos como otros de procedencia menos clara, los tenemos en estudio. Sin embargo, podemos adelantar que la cronología del cubilete se ha llevado desde el siglo xI al XIII (Ibidem, la segunda data debe recoger la hipótesis propuesta en RIu. M. 1960). Esta atribución tan imprecisa quizás tenga algo que ver con las anotaciones del señor Buchaca, según las cuales aparecieron fragmentos del vaso en el estrato de fundacion, en el pavimento y en la amortización del cuerpo de poniente, lo cual es, como minimo, equivoco (aunque, la mayor parte de los fragmentos se encuentran en las capas superiores). Por nuestra parte, deberemos realizar un análisis tipológico más detenido, que no impide nuestra preferencia hacia la fecha propuesta por el profesor M. Riu (con la que el profesor J. Cabestany se muestra de acuerdo, según nos ha indicado amablemente), que quizás concuerde mejor con el origen andalusi del material, constatado por las inscripciones en 
caracteres cúficos que presenta, las cuales hacen referencia a la ciudad de Sevilla y al nombre de Alá. De esta manera, podemos fijar la fundación del elemento que nos preocupa hacia el primer cuarto del siglo xı y concluir que su abandono pudiera ser del XIII, teniendo en cuenta la fecha de la cerámica vidriada, aunque para ello tuviésemos que suponer una parcial inexactitud de las anotaciones realizadas en 1960.

La función de este añadido también resultaba polémica, debido a su posición poco frecuente. En otras iglesias prerrománicas se dan naves mayores más largas que las laterales (p.e. Cuixà), pero ello obedece a una intención predeterminada por los constructores originales, y además en este caso el cuerpo debe incluirse en la arquitectura románica. Se ha dicho que pudiera haber sido un baptisterio, relacionándolo con el hallazgo de una pila bautismal, al parecer también románica (VIGUÉ 1985: 235, sin datación), en los alrededores de la iglesia y, de hecho, al final de la primera restauración, la pila se colocó en este lugar. La calificación de baptisterio traía aparejada necesariamente una comunicación con el resto de la iglesia, y ésta no podia sino realizarse a través de la puerta de la primera fase, que aún permanecia en el muro occidental (fue transformada en el siglo xIII; infra).

Nuestra opinión es que tal uso está poco justificado, pues, por ejemplo, nadie puede asegurar que la pila estuviese precisamente en este punto, pero, además, hemos realizado un hallazgo que podria sugerir la posibilidad de que el añadido fuese un porche. Se trata de dos capiteles trapezoidales o mensuliformes encontrados en la excavación del entorno de la fachada sur. Estas piezas, junto con fragmentos de fuste y elementos de la puerta del siglo $x$ ya citados (supra, 4.2), se descubrieron en un estrato de relleno depositado en la fase siguiente, para amortizar la plataforma escalonada que precedia la puerta meridional. Tales capiteles es lógico que sostuvieran arcadas geminadas y podrían ser de filiación románica. Además, su tipología es muy frecuente en los campanarios, y sobre ello volveremos al analizar la cronologia de un elemento de este tipo en nuestra iglesia (infra, 4.4). Sin embargo, también aparecen en los pórticos románicos más antiguos (de los que, por cierto, se conocen muy pocos). De este modo, como en la fachada de mediodia, donde estuvo el acceso principal desde el siglo $\times$, la topografía no permitia colocar un porche (el tamaño de la plataforma es minimo), éste pudo situarse en la entrada posterior. El muro macizo conservado hasta hoy no contradice esta hipótesis, porque precisamente se encuentra en el lado norte, donde otros porches son cerrados. No obstante, los capiteles podrian pertenecer a las desaparecidas paredes occidental y meridional. 

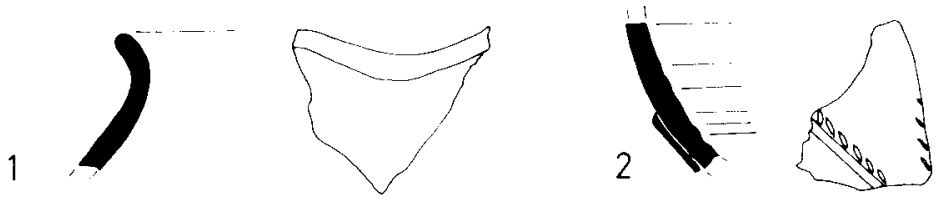

3

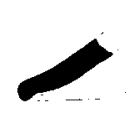

4

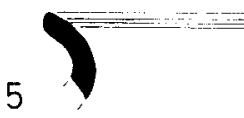

6

)
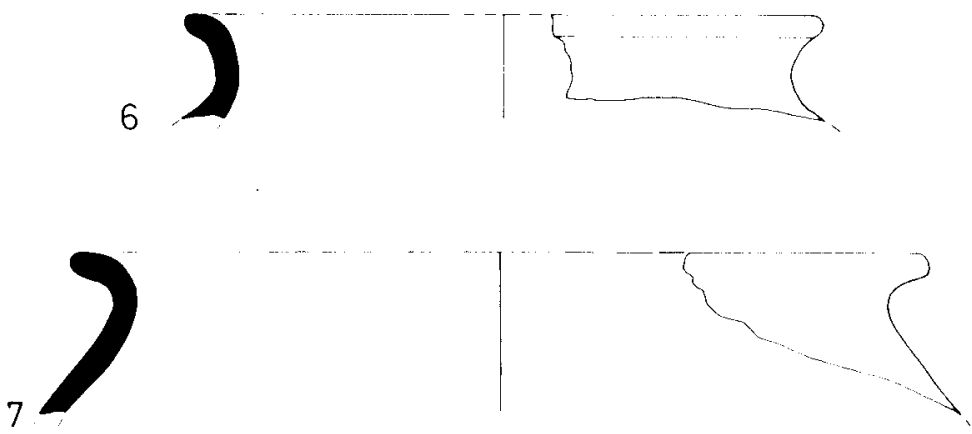

8
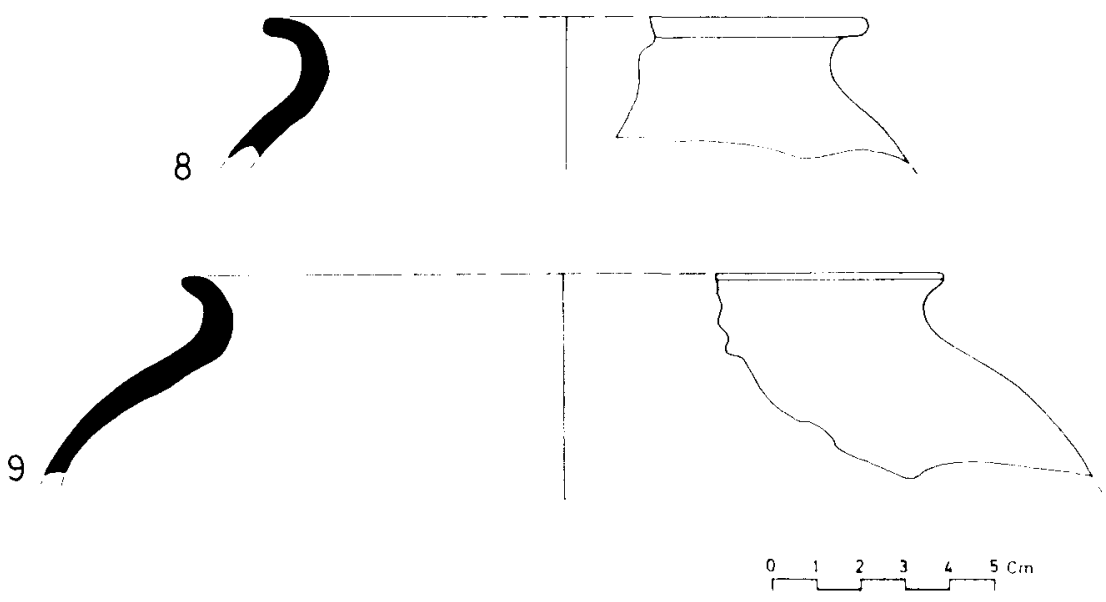

Lám. X. Materiales cerámicos caracteristicos de los siglos ix y $x$. 
La forma de estos elementos, propia de las ventanas de un campanario, se podria asimilar sin más a las teorias que atribuyen la función de campanil al cuerpo sudeste del edificio (PALLAS 1962: 66, siglo xI; SITJES 1977: 169, reproduce lo dicho por el otro autor). Sin desechar este aspecto, que más tarde trataremos, debemos dejar claro que es imposible la coexistencia de estas piezas y el cuerpo referido "tal como hoy lo conocemos", ya que su muro occidental se construyó después de amortizarse la parte arruinada de la nave sur, y esta amortización sabemos que se produjo en el siglo xili. No obstante, más adelante veremos que este muro quizá pudo ser posterior a un hipotético "primer» campanario. Por todo ello nuestras hipótesis sobre el porche son de momento provisionales.

Durante esta misma fase la absidiola norte fue objeto de reformas. Se trata básicamente de la refección de la bóveda y la ventana, de tal suerte que ésta adquirió una apariencia plenamente románica, con doble derrame y arco de medio punto, y aquélla modificó ligeramente su trazado original, adquiriendo tambièn una cornisa. No hay forma de fechar con precisión estos cambios porque la excavación del extradós de la bóveda no ha proporcionado material. Sin embargo, podemos utilizar algunos indicios; el primero de ellos es la homogeneidad de la nueva cubierta, demostrada en el excavación; el segundo, la posición de las pinturas románicas de finales de siglo $\mathrm{xI}$, cuyos restos ocupaban un sector del intradós de la cubierta mencionada; el tercer indicio pudiera ser la tipología de la cornisa. Al conocer con precisión la fecha de los murales (según se verá en el epigrafe siguiente), ya disponemos de terminus ante quem de hacia el 1075 para todas estas reformas, cuyo estilo románico ayuda a situar en el siglo xl; dentro de esta centuria, además, pueden ser algo tardias, teniendo en cuenta el tipo de cornisa empleado y la buena factura de la ventana. Por todo ello es licito suponer que las obras debieron llevarse a cabo muy poco antes de que la iglesia recibiera las nuevas pinturas murales, y quizás precisamente dentro de un plan general de embellecimiento y reparación (esta hipótesis ya fue planteada en GuDıOL 1937: 112-113, concretando una cronología del 1120, que hoy puede desecharse; PALLÁS 1962: 66, propone una data, a nuestro juicio, excesivamente alta dentro del siglo $\times 1)$.

Para terminar la descripción de la actividad edilicia en este momento, cabe referirse a la construcción del edificio a mediodia de la iglesia, en la terraza inmediatamente inferior. Ya hemos hipotetizado sobre su función (supra, 4.2), por ello basta decir que la excavación de uno de sus extremos (el resto se investigará próximamente, cuando la reparación de la cubierta garantice la seguridad indispensable para los trabajos) ha pro- 
porcionado el pavimento original, de arcilla con algo de cal, y una preparación apoyada en la roca con materiales del primer cuarto del siglo $\mathrm{xl}$.

\subsubsection{Las pinturas de finales del siglo $\mathrm{xl}$}

En el siglo xI la iglesia sufrió otro cambio importante en su imagen. Nos referimos a la ejecución de una serie de pinturas murales románicas de gran calidad. Se sabe que ocuparon el interior de las tres cabeceras, habiéndose conservado vestigios especialmente abundantes en la mayor y en la meridional. De la septentrional conocemos algunos fragmentos en el parámento del fondo y en el lado sur de la bóveda. Además, debe destacarse la existencia de pinturas en el muro oriental de la nave mayor y en el tercio este de la pared septentrional del mismo espacio. Las primeras, por cierto, silueteaban el arco triunfal de herradura y se extendian a su intradós. Los frescos de la absidiola sur se hallaban al descubierto a finales del siglo XIX, cuando fueron objeto de atención (MUNS 1887; PUiGGARI 1989), siendo arrancados y trasladados a Barcelona en 1922, conservándose en el Museo de Arte de Cataluña. Buena parte de los restantes murales fue descubierta en 1937, trasladándose dos años más tarde al Museo Diocesano y Comarcal de Solsona. Actualmente, en el edificio sólo quedan pequeños restos en la bóveda de la cabecera principal y algunas muestras más significativas, descubiertas durante la restauración de 1960 , en las paredes oriental y septentrional de la nave mayor.

Los extenso del conjunto y su riqueza iconográfica han propiciado numerosos estudios sobre el mismo (estado de la cuestion en: Yarza 1985: 218-234; aproximaciones posteriores en AINAUD 1989; WATSON 1989), de los cuales se deduce que debe datarse hacia el último cuarto del siglo $x i$. Esta fecha y los lugares donde fueron colocadas las pinturas ayudan a confirmar la evolución de algunos elementos del edificio. Por ejemplo, la embocadura del presbiterio trazada en el siglo $x$ avanzado subsistia en los últimos decenios del $x \mathrm{x}$, ya que las pinturas ornamentaron el arco triunfal y precisamente faltan en la zona de las impostas, modificada en el siglo xill. La presencia de murales en el lado meridional de la bóveda de la absidiola norte también indica que la remodelación de la misma ya se habia producido, teniendo en cuenta que nuestra excavación ha demostrado que toda la cubierta es sincrónica y que, además, se colocó al mismo tiempo que se modificaba la ventana. Por último, Gudiol (1937: 111113) advirtió secuelas de un incendio en los murales, lo que constî́uye un dato más para reconstruir lo acaecido en la fase siguiente.

\subsection{Cuarta fase, siglo xIII (lám. VI. a y b)}

Se trata de un periodo de gran actividad, probablemente provocada por un hecho accidental, pero también fruto de una vitalidad económica 
que pudo permitirla. Ya iremos viendo que las conclusiones de la excavación apuntan en este sentido, pero de momento deberemos retener que la mayoria de los legados a la iglesia conocidos son de entonces (SERRA 1985: 211). Esta circunstancia puede ser fortuita, incluso debida a la desigual conservación de los testimonios escritos. Sin embargo, no deja de ser sintomática.

En esta época se produjeron dos hechos decisivos y concatenados: la destrucción de una porción importante de la iglesia y la reconstrucción posterior de prácticamente todo el edificio, acercándolo al aspecto que tenía antes de comenzar la primera restauración, en 1959. Probablemente. un incendio acabó con la cubierta de madera de las naves y ocasionó el hundimiento de los dos tercios occidentales de la nave sur y de la mayor parte del añadido oeste. Como se ha dicho, Gudiol detectó el incendio estudiando las pinturas románicas. También, durante las primeras excavaciones, se localizó una capa de cenizas que cubria el pavimento de la fase anterior (BATISTA 1960: 6-8; BuchacA 1960: 5-9, 23-26). Sin embargo, el material encontrado en este estrato se perdió, y hasta ha resultado imposible establecer la cronologia del acontecimiento, al cual únicamente se le puede aplicar el terminus post quem del último cuarto del siglo xI, proporcionado por los murales.

Con todo, puede utilizarse otro elemento de juicio: la presencia del vaso andalusi encontrado en el cuerpo de poniente. Su fecha, por ahora, no se ha precisado, pero si aceptamos llevarla al siglo xIII, contando con que realmente apareciera en el estrato de derrumbamiento y/o amortización, tendremos un primer indicio para situar temporalmente esta fase. Afortunadamente no es el único, pues, como vamos a ver, el proceso de reconstrucción puede datarse a través de otras evidencias arqueológicas.

De la remodelación generalizada, que palió los efectos del incendio, tenemos muchos más datos. Sabemos que se cubrió la nave central con una bóveda de medio cañón apuntado, para lo cual hubo que regruesar interiormente sus paredes laterales, aligerando los muros resultantes con dos arcos formeros por banda. Inscritos en estos arcos, al norte, se instalaron capillas. En el sur, el más oriental daba paso a un nuevo espacio constituido al haberse cerrado a occidente el tercio este de la nave de mediodia. En todo el interior de los recintos citados se colocó un nuevo pavimento de mortero de cal y, para acceder al presbiterio, se dispusieron gradas también nuevas. Además, el arco triunfal del santuario se hizo de medio punto, alterando impostas y jambas, no por influencia de las modificaciones estáticas descritas, sino por un intento de aggiornamento estilistico. En la nave norte se instaló una cubierta de sección próxima al cuarto de cañón, aunque algo achatada. Paralelamente los dos tercios oc- 
cidentales del aula meridional quedaron abandonados, así como la plataforma exterior de acceso y sus gradas. Lo mismo ocurrió con los paramentos sur y oeste del añadido del poniente, donde sólo se conservó la pared norte, tal vez porque servía de muro de contención para las tierras de la montaña.

Este conjunto de actuaciones dio un cambio radical a la apariencia de la fábrica, y además restó al monumento algunos de sus caracteres hasta entonces emblemáticos. Por ejemplo, el regruesamiento de las paredes laterales de la nave central, al objeto de instalar, por primera vez, una bóveda, tuvo diversas consecuencias: ocultación de las pinturas románicas de la pared norte y de los extremos nordeste y sudeste del muro de levante; eliminación de la puerta de entrada en la fachada oeste, que se convirtió en ventana; ocultamiento de los arcos de herradura que comunicaban las naves laterales con la mayor; anulación como tales de la nave norte y su cabecera, que quedaron fuera de la vista de los fieles; desaparición de la ventana más alta del testero occidental, de la geminada oriental y de las aberturas del muro sur. La construcción de bóvedas sobre aulas eclesiales que carecian de ella es un hecho bien constatado en esta etapa, con paralelos numerosísimos. En nuestro caso bastará citar el idéntico proceso acaecido en los templos de Sant Jordi, dentro del mismo término de Cercs (LLOPART 1990) o en Sant Vicenç d'Obiols, perteneciente al vecino municipio de Avià, cuya trayectoria es muy similar a la de Pedret (PAllas 1962; Barral 1981: 178-179; JunYent 1983: 133-135.

La desaparición de un buen tramo de la nave sur también proporcionó al conjunto un aspecto muy característico. Por una parte, conllevó la colocación de la nueva puerta, desde la que se accedia directamente al espacio central, y por otra parte la aparición de un elemento formalmente nuevo: el cuerpo sudeste, obtenido al cerrar al oeste el antiguo tercio oriental de la nave sur (lám. XIV). Tanto una como otra operación presupusieron el arrasamiento completo y la desaparición visual de los restos de la nave que salió peor parada del incendio. Ello se consiguió mediante el vertido de los rellenos ya aludidos que, además, se extendieron fuera de lo que habia sido el recinto religioso, pues, al eliminarse también la antigua plataforma escalonada de mediodia, convenía terraplenar todo el entorno de ese lado, para facilitar el acceso de los fieles (lám. VIII.1). A pesar de todo, la antigua concepción del extremo meridional no debió cambiar radicalmente: sobre las ruinas de los muros perimetrales arrasados, se erigió un porche (sus ruinas se han localizado en nuestra excavación) de estructura débil, pero suficiente para mantener la calidad espacial (fig. *). Este elemento, al cabo, era imprescindible, ya que, desaparecido el añadido de poniente, que cumplia la misma función, y eliminada la plataforma sur, se tenian razón y lugar para construirlo. 
El cuerpo sudeste, que acabamos de citar, sabemos que cumplió una doble función en su nivel inferior pues, de una parte era tránsito a la antigua absidiola sur y de otra albergaba un nuevo altar, construido al fondo (descubrimiento de la lipsanoteca, que ha desaparecido, en BUCHACA 1960: 1). Sin embargo, su cubierta y, mejor aún, su estructura general sugieren que debió alcanzar mayor altura que la actual. Se ha dicho que pudo ser un campanario (PALLÁs 1962; 66; SITJES 1977: 169), y con ello estamos de acuerdo, teniendo en cuenta el arco de descarga situado a mediodia de la entrada (todavía se conserva). Su cronologia también ha sido objeto de discusión y sobre tal cuestión nos extenderemos más adelante. Igualmente trataremos de su aspecto truncado, que ha sido interpretado repetidamente como signo inequivoco de inconclusión.

El proceso descrito hasta aqui se puede situar en el tiempo mediante evidencias arqueológicas. Las primeras, proporcionadas por los trabajos de hace años, son el descubrimiento del pavimento contemporáneo de esta reforma y de una moneda de Jaime I, hallada en el escalón del presbiterio que se le relacionaba. Las restantes, fruto de nuestra excavación, son las siguientes: Ia posición estratigráfica del muro occidental del cuerpo sudeste, cortando los estratos anteriores y relacionado con los suelos, exterior e interior de esta época; la situación de la puerta actual, relacionada con el mismo pavimento y solidaria del arco formero que la enmarcó interiormente; la amortización de los tres silos que funcionaban desde el siglo $x$, en cuyo interior, además de ceniza, tierra y piedras, se hallaron diversos fragmentos de cerámica gris de finales del siglo xll y primera mitad del XIII aproximadamente (lám. XI); el estrato de relleno exterior, ya aludido al tratar de los capiteles mensuliformes, que proporcionó otra moneda de Jaime I, más cerámica gris y fragmentos de una olla de pasta oxidada con vedrio verde; un segundo estrato de idéntica función, depositado al oeste de las ruinas de la nave sur, con otra pieza del monarca citado.

Los materiales de estas unidades estratigráficas están en estudio. Sin embargo, aunque algunas piezas grises pudieran proceder del alfar de Casa en Ponç (Berga; sobre su producción, cf. Botós RIu, C., 1985; 129130, finales XI1-principios xil, según datos de PADHLA 1983-1984: 99-143; M. Riu nos informa amablemente que existen documentos inéditos los cuales denotan la inactividad del taller en el primer decenio del siglo $x(111)$, otras deben ser posteriores. El vaso andalusi antes citado, cuya cronologia también parece algo tardia, debe ser analizado con mayor profundidad. Las monedas, mucho más fácilmente identificables, ya se han clasificado: en su totalidad fueron emitidas en tiempo del rey conquistador (12131276), y abarcan un largo periodo de uso, todavía más prolongado por su circulación en ciertas zonas ( $p$. ej. Valencia) hasta la época de Pedro VI 
ALBERTO LÓPEZ MULLOR Y ALVAR CAIXAL MATA
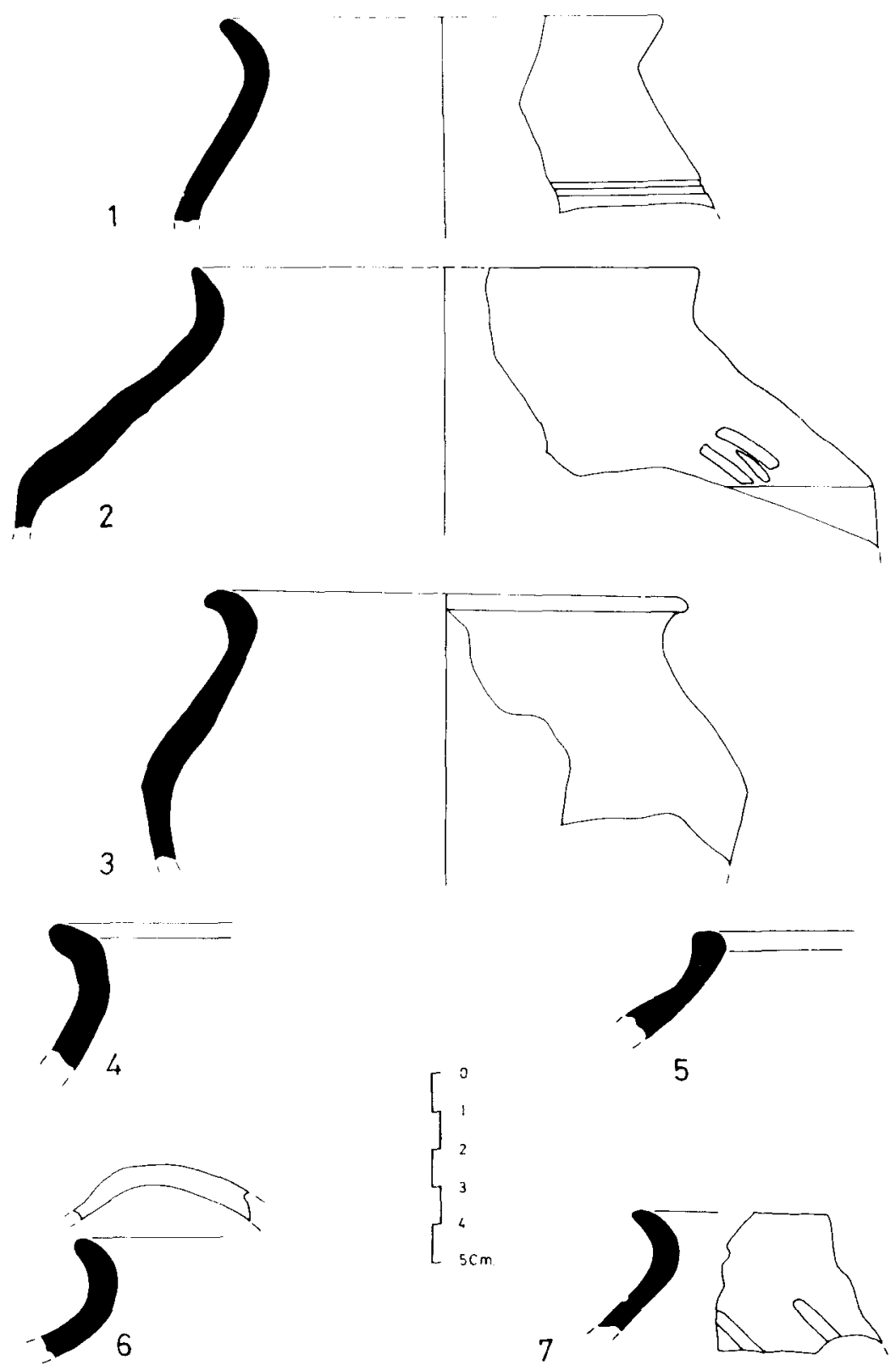

Lám. XI. Materiales cerámicos caracteristicos de los siglos XI-XIII.

364 
(1336-1387). Por fin, el estilo de la portada, perteneciente al románico epigona!, no proporciona una datación precisa (VIGUE 1985: 216, fines siglo $\mathrm{XI}$-principios $\mathrm{XIII}$ ), tal vez porque faltan paralelos de fecha segura. No obstante, puede observarse que tiene cierto parecido con las de Sant Diumenge de Su (CAMPS 1987: 267-268, fines siglo XII-principios XIII), Sant Pau de Casserres (Junyent, F., MAZCuñan 1985: 156-157, siglo xil avanzado) y Sant Bartomeu de Valldan (VILADÉs 1985: 127, s/f.). Todo ello, por ahora dificulta el establecimiento de una cronologia absoluta bien perfilada para los acontecimientos descritos, pero sin duda pueden situarse en el siglo xIII, quizás a partir del segundo cuarto, data probable de la amortización de los silos y de la reforma de la capilla mayor

Estos cambios no habian pasado desapercibidos en la bibliografía anterior, y cuantos autores hicieron referencia al edificio los identificaron total o parcialmente. Algunos, dado lo temprano de sus apreciaciones (Puig i Cadafalch, Falguera, Goday 1909: 369; Gómez Moreno 1919: 59), no contaban con más evidencia que la observación de la fábrica, y trataron, con mayor o menor fortuna, de explicar su evolución. Los primeros investigadores citados, conocedores de una referencia al templo en 1180 (dificilmente comprobable), y observando la factura de la portada y la cu-
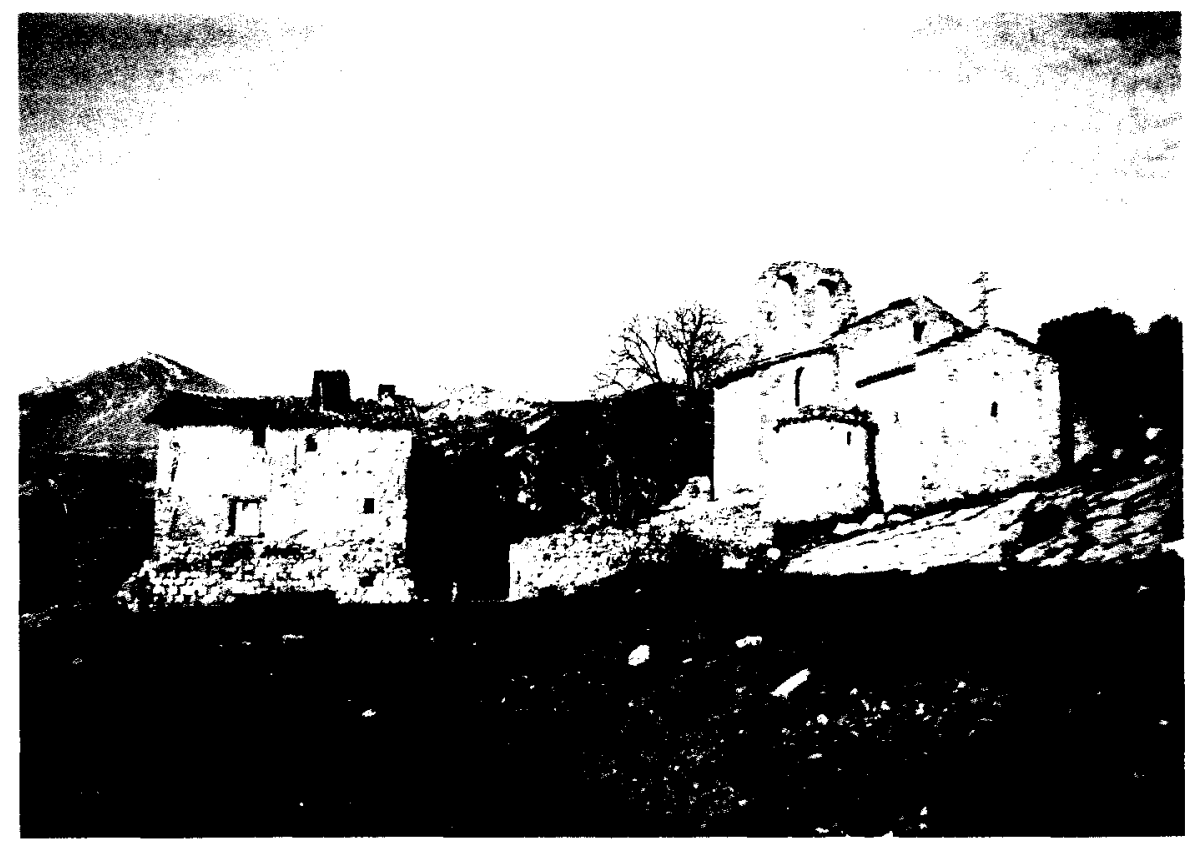

Lám. XII.1: vista general del conjunto en 1989. 


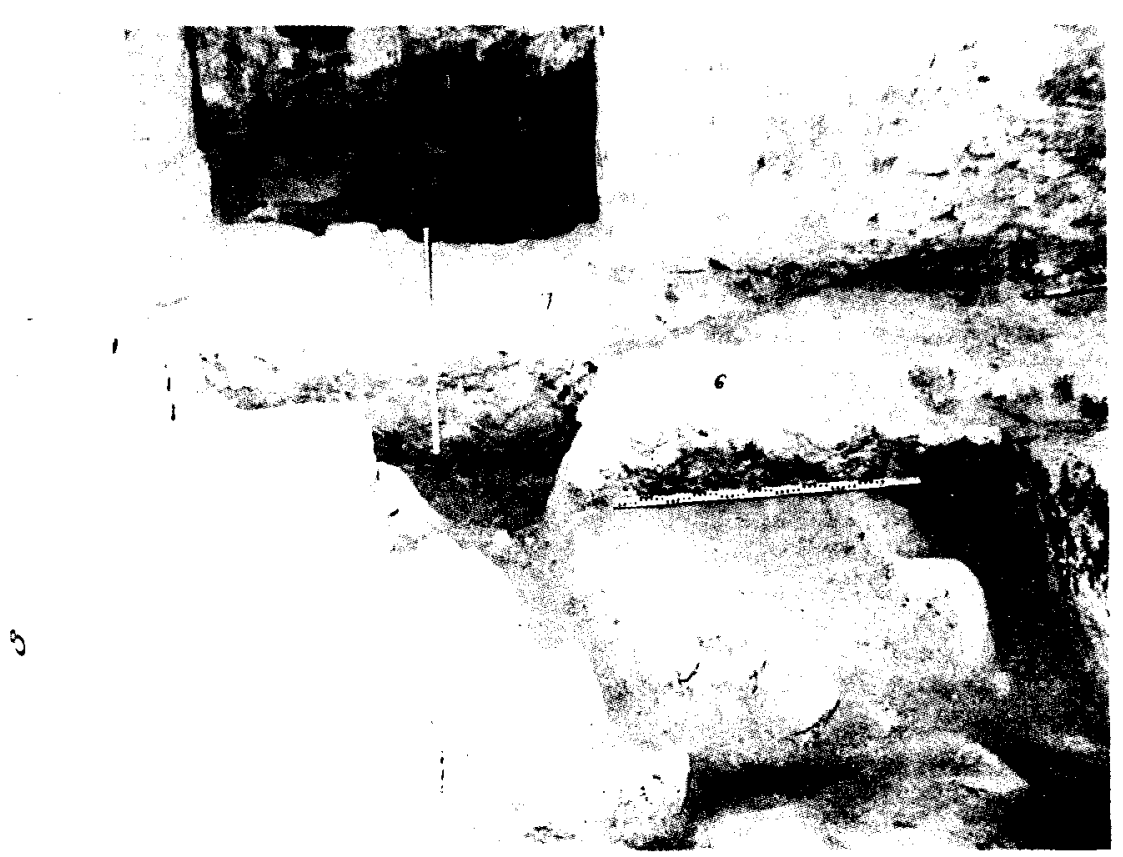

Lám. XII.2: detalle de la excavación; se advierte el arrasamiento de parte del muro meridional del siglo ix para abrir el arco de comunicación con la nave colateral de mediodia, edificada en el siglo $x$

bierta de la nave central, situaron en un periodo próximo a aquella fecha la construcción de ambos elementos, asi como la destrucción de parte de la nave sur, imprescindible para poder erigir el nuevo acceso. El segundo tratadista consideró que la bóveda del aula mayor y la puerta de mediodía eran obra del siglo XII, asi como la refección de la absidiola norte, no mencionada por los anteriores.

Gudiol, que trabajó en la iglesia en 1937, pudo comprobar los efectos de un incendio sobre los murales románicos (Gudiol 1937: 111-113), siendo el primero en mencionarlo, situándolo hacia 1150. Esta fecha, en principio, no tiene más base que la intuición, y parece el resultante de considerar las pinturas de principios del siglo XII (ca. 1120; cronologia que se les atribuyó sistemáticamente durante muchos años) y suponer un mínimo periodo de uso hasta que fueran afectadas por las llamas. Además, el autor intentó realizar un análisis global de todos los cambios que advertía en la fábrica. A los efectos del incendio atribuyó la desaparición de la cubierta de la nave central, creyendo que en este lugar se habria intervenido al poco, es decir, hacia mediados del siglo xII, dotándolo de su apariencia actual. Sin embargo, su hipótesis sobre la colocación de la 
portada a principios del XII, coincidiendo con las pinturas murales (Ibidem, 112), resulta incoherente, pues presupone la desaparición de la nave sur, a la cual no hace la más minima referencia. Según su opinión, también serian del siglo xII inicial la reforma del ábside norte y una primera bóveda de la nave del mismo lado.

Pallás (1962) disponía de muchos más elementos de juicio, ya que durante la primera restauración se descubrieron testimonios decisivos para conocer la evolución del edificio. De este modo, pudo afirmar con seguridad que la reforma del santuario, la cubierta de la nave central y la portada correspondian a la época de Jaime I (las monedas encontradas lo confirmaban sin ambages). También aludió al incendio con conocimiento de causa. Sin embargo, algunos elementos entonces peor estudiados recibieron cronologias menos precisas. Asi, el cuerpo sudeste que se consideró campanario, a nuestro juicio acertadamente, se situó en el siglo XI, durante el obispado/abaciado de Oliba. La reforma de la absidiola norte se situó en la misma fecha (Ibidem, 66), lo que no desdice demasiado de nuestras propias conclusiones.

De todos modos, las evidencias aportadas por este arquitecto restaurador, no han sido creidas por todos, a lo mejor porque no se presentaron extensamente. Sitjes (1977: 169), las siguió en parte complementándolas con las teorias de Gudiol, lo que proporcionaba un panorama bastante coherente en sí mismo. Así, en el siglo XII, a raiz del incendio, se modificaba la absidiola norte y se construían la portada y el campanario, pues el tramo occidental de la nave sur se habia hundido. Las nuevas bóvedas mayor y septentrional y la retocada embocadura del presbiterio eran del siglo xIII. Junyent (1983: 142-143), sitúa todos estos cambios a principios del siglo xII, en un solo momento y sin dar demasiadas explicaciones. Por último, un reciente estado de la cuestión (Pons 1985: 214-215) concentra, no $\sin$ muchas dudas, los acontecimientos descritos en esta fase hacia finales del siglo XII o principios del XIII.

Como se verá, los investigadores que nos han precedido han realizado una extensa aproximación a los hechos. De ella se deduce que hay cuestiones claramente comprobadas, como la cronología de las bóvedas central y septentrional, la portada y la modificación de la entrada al presbiterio, todo ello en época de Jaime I. Los datos presentados por Pallás, basados en evidencias arqueológicas que ya hemos comentado ampliamente, son incontestables y últimamente lo hemos comprobado y acrecido. Lo mismo ocurre con la destrucción de una parte de la nave sur, condición indispensable para colocar el nuevo portal. Esta destrucción, sin embargo, bien fechada en las últimas excavaciones, se relaciona estratigráficamente con el muro de poniente del campanario y nos da una da- 
tación de esta pared también dentro de la época del Conquistador. Asi tendriamos la fecha de este campanario, aunque no podemos descartar qué parte de su estructura hubiese funcionado anteriormente. Nos referimos a los muros meridional, oriental y sobre todo septentrional (los dos primeros apoyados en paramentos del siglo $x$ y el segundo en un lienzo del $\mathrm{x}$ recrecido también en el $\mathrm{x}$ ). El análisis de este último, realizado conjuntamente con los arquitectos de nuestro equipo, indica a las claras que fue construido directamente sobre la pared de separación entre las naves mayor y meridional, cuando tal paramento todavía no habia sido regruesado (por eso sólo en este sector del muro se conservaron los orificios de las cerchas de la cubierta de madera, eliminados en el resto durante la intervención del siglo $\times 111$ ). Así las cosas, es indudable que se trata de una estructura anterior a la de la bóveda de medio cañón apuntado, aunque resulta imposible saber "cuánto".

Debemos descartar su paralelismo formal con los añadidos de principios del siglo xi (supra, 4.3.1), por las evidentes diferencias de su aparejo con el de aquéllos, extremadamente característico y fácilmente identificable, pero muy poco semejante al del elemento que ahora nos ocupa. De este modo, podemos saber que el "primer» campanario existió sin duda alguna, siendo posterior a las construcciones del siglo $x$ y anterior a la bóveda del xIII, y, en el supuesto de una cronología alta dentro de la horquilla enunciada, los capiteles encontrados en el relleno de este mismo siglo depositado al sur de la iglesia podrian haberle pertenecido. Si, por el contrario, nos decantamos por una cronología baja, seguramente más plausible teniendo en cuenta su aparejo y la forma de sus ventanas, los referidos capitales habrian pertenecido al pórtico, posibilidad que antes hemos apuntado (4.3.1).

De esta manera, el "segundo" campanario, cuya configuración general ha llegado a nosotros poseería un elemento de mediados del siglo xill, el muro occidental dotado de una ventana más ancha y baja que las otras, adaptada para convivir con la cubierta del nuevo porche descrito más arriba, y otros elementos precedentes, acaso del siglo $\mathrm{xl}$ avanzado o del xII, cuyo derrumbe parcial, al principio de la etapa que nos ocupa. tal vez ocasionó la ruina de la frágil estructura de un buen tramo de la nave sur. Por último, respecto al aspecto truncado del elemento, tal y como hoy lo conocemos, no resulta lógico suponer que obedece a su inconclusión. Tanto en la época del "primer» como del "segundo" campanario se disponia de medios suficientes para terminarlo, a juzgar por la envergadura del resto de las reformas realizadas. Por ello la única explicación que hallamos lógica para mantenerlo con este aspecto - si es que se hizo asi- es la erección de una espadaña de dos ojos en el siglo xIII, apoyada en el testero occidental de la iglesia. Sabemos que tal construcción se 


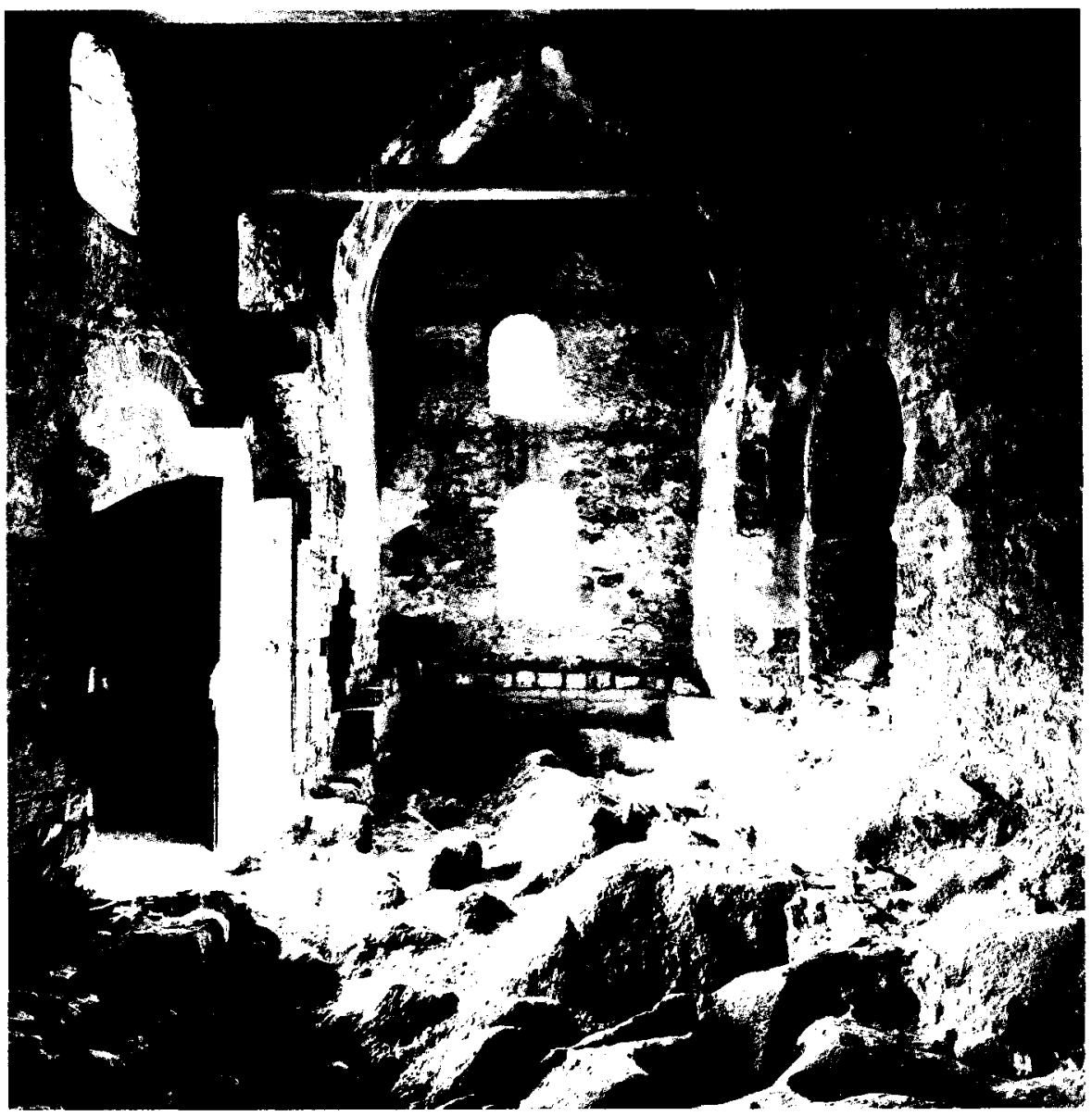

Lám. XIII. Interior de la iglesia después de completarse su reexcavación.

llevó a efecto pues, durante la excavación del intradós de la bóveda de cañón apuntado, han aparecido los orificios para las cuerdas de dos campanas, en un lugar a propósito para accionar las que debió tener la espadaña antecesora de la actual.

Por lo que se refiere a la absidiola norte, el pavimento del siglo $x$ hallado en su interior justifica que su perimetro actual sea del mismo momento; la cubierta y la ventana, en cambio, están claramente rehechas y su cronología sólo puede deducirse a través de la posición en las mismas de las pinturas románicas (supra, 4.3.2). Sin embargo, ninguno de los au- 


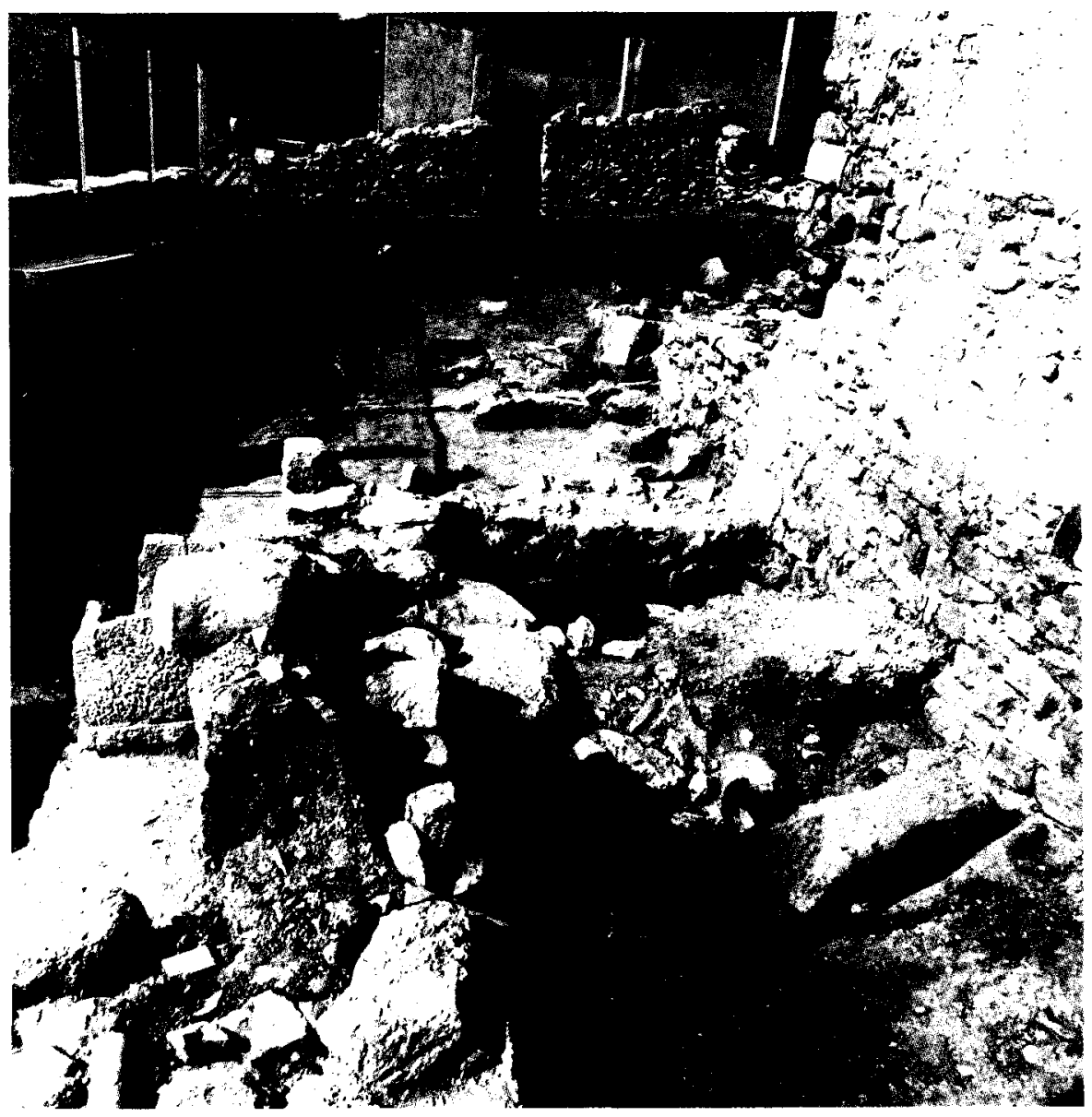

Lám. XIV. Vista parcial de las ruinas de la nave sur: a la derecha dos silos del siglo $x$ y al fondo terrazas del $x$ perforadas por diversas tumbas fechadas del $x$ al $x I I I$

tores que se han ocupado de ellas acierta a concretarla. Quizás, un fragmentito, hoy desaparecido o perdido en algún almacén, debió estar en la cubierta (GuDIOL 1937: 109). De ser asi, deberiamos aceptar que ésta fue rehecha antes de ser pintada; es decir, en el momento que propone Gudiol, aunque su cronología absoluta difiera de la que nosotros utilizamos, fruto del estudio de Yarza. 
VI. EPILOGO (lám. VII, a y b)

Durante la época moderna, la iglesia experimentó algunos cambios que le dieron un aspecto muy cercano al que perduró hasta la primera restauración. Tales modificaciones deben fecharse hacia principios del reinado de Felipe V. Esta cronología la conocemos a través del hallazgo de un buen número de monedas, emitidas por el archiduque Carlos durante la guerra de Sucesión (1701-1714). Tales piezas, acuñadas en Barcelona y fechadas entre 1708 y 1711, suelen ser el fósil director de multitud de estratos de la época. Su nulo valor después de la desmonetización que siguió al conflicto (1719) hizo que se desecharan, y se encuentran en abundancia junto con alguna pieza del primer Borbón, aunque éste no es el caso de Pedret.

En nuestro yacimiento, este numerario, junto con algunas monedas más antiguas y fragmentos de cerámica actualmente desaparecidos, ocupaba la preparación de un pavimento de losetas cerámicas, que se mantuvo in situ hasta 1959, ocupando todo el interior del edificio. La posición de este suelo dentro de la secuencia estratigráfica indica que todo se habia mantenido prácticamente igual desde las reformas del siglo xill. No obstante, debe reseñarse que entonces se modificó el altar al fondo del cuerpo sudeste, según indican monedas del mismo tipo que las citadas, halladas en su interior. Seguramente, a la sazón, también pudo tapiarse la embocadura de la absidiola sur.

Lo que no queda tan claro es cuándo se abrieron las puertas de comunicación entre las capillas laterales y la mayor (lám. I.1). Sin duda, fue después de haberse aplicado los murales de finales del siglo xI, pues las puertas las rompieron, y antes de colocarse el nuevo suelo de losetas, ya que éste cubría los umbrales de ambos accesos. En relación con la absidiola norte, acaso deba pensarse en la apertura de una comunicación ya en el siglo XIII, pues entonces quedó cegado el paso entre las naves de aquel lado y la central. Quizás no debió ocurrir lo mismo al sur y, cuando por fin quedó tapada la embocadura, se abrieron las dos puertas.

En el exterior, la sobreelevación de la cubierta de la capilla mayor para instalar un horno doméstico y la erección de la espadaña actual también deben ser de aquel momento. Uno y otro elemento poseian escaleras de acceso desde el norte, el inicio de las cuales coincidia con la cota de un suelo muy elevado, el cual se consiguió a base de acumular abundantes tierras. Su excavación nos ha proporcionado materiales de este periodo. La espadaña barroca tal vez sustituyó al campanario, derruido en un momento que desconocemos o, si aceptásemos las teorias de Pallás (1962: 66), siguió cumpliendo la función que no pudo llegar a tener este 
elemento por encontrarse inacabado (o tal vez no «reconstruido», según nuestras hipótesis).

Volviendo al interior del edificio, es notorio que poseyó un coro a los pies de la nave mayor, desmontado durante las obras de 1959-1964. Su última estructura era de madera, accediéndose por una escalera colocada a mediodia. No obstante, el muro presenta la impronta de otra anterior. El paralelismo de este elemento con los de iglesias vecinas nos indica que bien pudo ser del siglo XVIII. Lo mismo ocurre con un banco corrido, situado al fondo del aula principal que, según parece, descansaba sobre el suelo de losetas, por lo que habremos de considerarlo ligeramente posterior, dentro de la misma centuria.

Para terminar, debemos hacer referencia a un gran número de sepulturas de inhumación aparecidas a mediodia y levante de la iglesia. Su rito era muy simple y su orientación diversa. El escaso ajuar aparecido hace que puedan situarse desde el siglo XVII al XIX, principalmente. A falta de otros testimonios, son el mejor exponente para evidenciar un uso continuado del edificio durante un periodo en el que apenas sufrió modificaciones, y también para reafirmar su condición parroquial durante aqueIla época.

\section{BIBLIOGRAFIA}

A.A. V.V. 1991: “Actuaciones en el patrimonio edificado medieval y moderno (siglos x-xVIII)", Quaderns Científics $i$ Tècnics, 3. Servei del Patrimoni Arquitectònic de la Diputació de Barcelona. Barcelona.

AINAUD, J. 1989: La pintura catalana. La Fascinación del Románico. Barcelona.

Bango, I. G. 1974: "Arquitectura de la décima centuria: ¿Repoblación o mozárabe?", Goya (Madrid), 122: 68-75.

Batista, R. 1960: Diario de la excavación en la iglesia de Sant Quirze de Pedret (inédito).

BARRAL, X. 1981: L'art pre-romànic a Catalunya. Segles $1 x-x$. Barcelona.

Bolos, J.; Rıu, C. 1985 a: "Berga. Forns de ceràmica de Casa en Ponç", Catalunya Románica. XII. El Berguedà. Barcelona: 129-130.

- 1985 b: Cercs. "Sant Quirze de Pedret. Ceràmica”. Catalunya Romànica. XII. El Berguedà. Barcelona: 235-236

BoLòs, J.; PAGÉS, M. 1981-182: "Les sepultures excavadas a la roca", Necrópolis $i$ sepultures medievals a Catalunya, annex 1 d'Acta Mediaevalia. Barcelona: 59-103.

Buchaca, M. 1960: Diario de la restauración de la iglesia de Pedret. Berga, 14 de diciembre de 1959-junio de 1960 (inédito).

CAMON AZNAR, J. 1949: "Arquitectura española del siglo x; mozárabe y de la repoblación", XVI Congreso Internacional de Historia del Arte: 106-123 = Goya (Madrid), 52, 1963: 206-219.

CAMPS, J. 1987: «Riner. Sant Diumenge de Su. Portada", Catalunya Romànica. XIII. El Solsonès. La Vall d'Aran. Barcelona: 267-268.

Gomez Moreno, M. 1919. Iglesias mozárabes. Arte español de los siglos ix a xı. Madrid: 5963. 
Gomez Moreno, M. 1951: “Arte mozárabe", Ars Hipaniae, |ll.

González, A. 1985: Recerca i disseny. El monument com a document históric i com a objecte arquitectonic viu. Barcelona (con traducción al castellano).

- 1990: “A la recerca de la Restauració Objectiva». Memòria 1985-1989, Servei del Patrimoni Arquitectònic de la Diputació de Barcelona. Barcelona: 7-12 (con traducción al castellano).

GROS, M. S. 1975: "La liturgie narbonnaise témoin d'un changement rapide des rites liturgiques", Liturgie de l'Eglise Particulière et liturgie de l'Eglise Universelle. Roma: 127154.

- 1990: "Las tradiciones medievales en el noroeste de la peninsula", IX Centenário da dedicaçäo da sé de Braga. Congresso Internacional. Actas, vol. III. Teologia do Templo e Liturgia Bracarense. Braga: 103-115.

Gudiol, J. 1937: «Pedret». Butlleti del Centre Excursionista de Catalunya (Barcelona), XLVII, n. ${ }^{\circ}$ 504: $107-113$.

JUNYENT, E. 1983: L'arquitectura religiosa a Catalunya abans del romànic. Barcelona.

Junyent, F,; Mazcunan, A. 1985: "Casserres de Berguedà. Sant Pau de Casserres. Portada", Catalunya Romànica. XII. El Berguedà. Barcelona: 156-157.

LACuesta. R. (coord.). 1986: Diputació de Barcelona: setanta anys de catalogació i conservació de monuments. Barcelona.

LoPez Mullor, A. 1986: “Consideracions metodològiques sobre l'actuació del Servei de Catalogació i Conservació de Monuments en el camp de la recerca arqueológica". Memória 1984, Servei de Catalogació i Conservació de Monuments de la Diputació de Barcelona. Barcelona: 19-21, 158-160, 214-215 (con traducción al castellano).

- (dir.) 1989: Recerques hitòrico-arqueològiques al Berguedà (1983-1986). Església de Sant Vicenc de Rus. Església de Santa Eulàlia de Gironella. Pont Vell de la Pobla de Lillet. Servei del Patrimoni Arquitectònic de la Diputació de Barcelona. Barcelona.

- 1990: "Set anys d'investigació arqueològica del patrimoni arquitectònic", Memória 19851990. Servei del Patrimoni Arquitectònic de la Diputació de Barcelona. Barcelona: 13-18 (con traducción al castellano).

- 1991: "La excavación del monasterio de Sant Llorenç prop Bagà. Campañas 1984-1989". Actuaciones en el patrimonio edificado medieval y moderno (siglos $x-x v m$ ), Quaderns Científics i Tècnics, 3, Servei del Patrimoni Arquitectònic de la Diputació de Barcelona. Barcelona: $67-89$.

Lopez Mullor, A.; Caixal. A. 1991: “Resultados de las excavaciones realizadas en el monasterio de Sant Llorenç prop Bagà (Guardiola de Berguedà, Barcelona). Campañas 19841987 ", Congreso Internacional "Historia de los Pirineos". Cervera-noviembre 1988. Madrid: $243-258$.

Llopart, J. 1990: “Església de Sant Jordi de Cercs. Noticia Historica", Memória 1985-1990, Servel del Patrimoni Arquitectónic de la Diputació de Barcelona. Barcelona: 70-73, 7576 (con traducción al castellano).

Muns, F. 1987: "Sant Quirce de Pedret», Certamen Catalanista de la Joventut católica de Barcelona. Barcelona.

Mundo. A. M. 1971: "Les changements liturgiques en Septimanie et en Catalogne pendant la periode preromane", Les Chaiers de Saint-Michel-de-Cuixà (Perpinyà), 2: $29-42$.

PADILla, J. I. 1983-1984: "Contribución al estudio de las cerámicas grises catalanas de la época medieval: el taller, los hornos y la producción de Casampons", Ceràmica grisa i terrissa de la Catalunya Medieval. Anexo II de Acta Mediaevalia. Barcelona: 99-143.

PALLAS, C. 1962: “Arte prerrománico catalán: Pedret y Obiols», San Jorge. (Barcelona), 47: 63-67.

Pons, J. 1985: “Cercs. Sant Quirze de Pedret. Arquitectura», Catalunya Romànica. XII. El Berguedá. Barcelona: 213-215.

Pladevall, A. 1989: Historia de l'Església a Catalunya. Barcelona.

Ponsich, P. 1948: "Les deus églises mozarabes de Sournia (Pyrénées-Orientaux)», Anales y Boletin de los Museos de Arte de Barcelona (Barcelona). VI: 297-311. 
PONSICH, P. 1983: "L architecture religieuse préromane des pays de Roussillon, Conflent, Vallespir et Fenolledés", Les Chaiers-de-Saint-Michel-de-Cuxa (Perpinyà), 14 (separata sin paginación).

Puertas Tricas, R. 1975: Iglesias hispánicas (siglos iv al vili). Testimonios literarios. Madrid.

Puig I CAdafalch, J. 1928: Le premier art Roman. Paris

Puig I Cadafalch, J.; Falguera, A. de; Goday, J. 1909 (2. ${ }^{a}$ ed. 1983): L'Arquitectura Romànica a Catalunya. I. Precedents: l'Arquitectura Romana, l'Arquitectura Pre-Románica. Barcelona.

Puigggarl, J. 1889 (25 de julio): “Pintures murals de Pedret”. L'Avenc (Barcelona), I.

RiBAs, M. 1967: "Una necrópolis romana en la basilica de Santa Maria del Mar de Barcelona", Ampurias, XXIX: 197-198.

- 1975: El Maresme en els primers segles del cristianisme. Barcelona.

Rıu, M. 1960 (5 de junio): "Mirando al pasado. Disección de Sant Quirze de Pedret", Diario de Barcelona.

- 1980: "Estado actual de las inveśrigaciones sobre las cerámicas catalanas de los siglos IX al XIV", La céramique médievale en Mediterranée Occidental X-XIV siècle. Valbonne 11-14 septembre 1978. Paris: 385-395.

- (dir.) 1981-1982: "Necrópolis i sepultures medievals a Catalunya", anexo 1 de Acta Mediaevalia. Barcelona.

- : Estat actual de les recerques sobre les ceràmiques grises i la terrissa popular de la Catalunya medieval», La Ceramica Medievale nel Mediterraneo Occidentale. Siena 1984. Florencia: $219-225$.

RIU, E. 1984: "D'algunes formes de terrissa alt-medieval barcelonina", Cerámica grisa i terrissa popular de la Catatunya Medieval, anexo 2 de Acta Mediaevalia. Barcelona: 2948.

Rodriguez de Ceballos, A. 1965: "El reflejo de la liturgia visigótico-mozárabe en el arte español de los siglos VIII-X”, *: 295-327.

RosselL, R. 1985: "Cercs. Sant Quirze de Pedret. Pintures murals, Catalunya Románica. XII. El Berguedá. Barcelona: 216-218.

SAlLÉS, P. 1985: "Guardiola de Berguedà. Sant Llorenç prop Bagà. Acta de consagració de l'eglésia de Sant Miquel de Sant Llorenç", Catalunya Romànica. XII. El Berguedà. Barcelona: 291.

SerRa, R. 1985: "Cercs. Sant Quirze de Pedret. Història", Catalunya Romànica. X/l. El Berguedà. Barcelona: 210-213.

SitJes, X. 1977: Les esglésies pre-romàniques de Bages, Berguedà i Cardener. Manresa.

VIGue, J. 1985: "Cercs. Sant Quirze de Pedret. Portada, lipsanoteques, encenser, pica baptismal, escultura sobre pedra, ferro forjat", Catalunya Romànica. XII. El Berguedà. Barcelona: $216,234-236$.

VILADES, R. 1985: "Berga. Sant Bartomeu de la Valldan. Arquitectura", Catalunya Romànica XII. El Berguedà. Barcelona: 127.

Watson-Al Hamdani, B. 1989: "Reconstrucció curosa de les pintures de Sant Quirze de Pedret amb una visió àmplia del conjunt", L'Erol (Berga), 27: 15-24.

- 1990: "Interpretació d'un antic fresc de Sant Quirze de Pedret", L'Erol (Berga), 31: 3338.

YarzA, J. 1985: "Cercs. Sant Quirze de Pedret. Pintura mural», Catalunya Románica. XII. El Berguedà. Barcelona: 218-234. 